\title{
Adenylyl cyclase 5-generated cAMP controls cerebral vascular reactivity during diabetic hyperglycemia
}

\author{
Arsalan U. Syed, ${ }^{1}$ Gopireddy R. Reddy, ${ }^{1}$ Debapriya Ghosh, ${ }^{1}$ Maria Paz Prada, ${ }^{1}$ Matthew A. Nystoriak, ${ }^{2}$ Stefano Morotti, ${ }^{1}$ \\ Eleonora Grandi, ${ }^{1}$ Padmini Sirish, ${ }^{3}$ Nipavan Chiamvimonvat, ${ }^{1,3,4}$ Johannes W. Hell, ${ }^{1}$ Luis F. Santana, ${ }^{5}$ Yang K. Xiang, ${ }^{1,4}$ \\ Madeline Nieves-Cintrón, ${ }^{1}$ and Manuel F. Navedo ${ }^{1}$
}

'Department of Pharmacology, University of California, Davis, Davis, California, USA. ²Diabetes and Obesity Center, Department of Medicine, University of Louisville, Louisville, Kentucky, USA. ${ }^{3}$ Department of

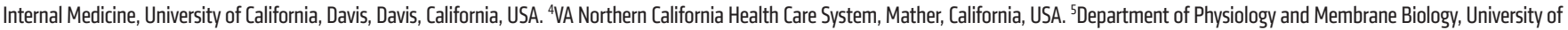
California, Davis, Davis, California, USA.

\begin{abstract}
Elevated blood glucose (hyperglycemia) is a hallmark metabolic abnormality in diabetes. Hyperglycemia is associated with protein kinase A-dependent (PKA-dependent) stimulation of L-type $\mathrm{Ca}^{2+}$ channels in arterial myocytes resulting in increased vasoconstriction. However, the mechanisms by which glucose activates PKA remain unclear. Here, we showed that elevating extracellular glucose stimulates CAMP production in arterial myocytes, and that this was specifically dependent on adenylyl cyclase 5 (AC5) activity. Super-resolution imaging suggested nanometer proximity between subpopulations of AC5 and the L-type $\mathrm{Ca}^{2+}$ channel pore-forming subunit $\mathrm{Ca}_{\mathrm{v}}$ 1.2. In vitro, in silico, ex vivo, and in vivo experiments revealed that this close association is critical for stimulation of L-type $\mathrm{Ca}^{2+}$ channels in arterial myocytes and increased myogenic tone upon acute hyperglycemia. This pathway supported the increase in L-type $\mathrm{Ca}^{2+}$ channel activity and myogenic tone in 2 animal models of diabetes. Our collective findings demonstrate a unique role for AC5 in PKA-dependent modulation of L-type $\mathrm{Ca}^{2+}$ channel activity and vascular reactivity during acute hyperglycemia and diabetes.
\end{abstract}

\section{Introduction}

Vascular complications during diabetes are major risk factors for cardiovascular diseases, including stroke and hypertension (1), and are often linked with elevated blood glucose (i.e., hyperglycemia; refs. 2-4). Although the advantages of glycemic control to improve cardiovascular outcome in diabetic patients are well recognized, additional strategies targeting underlying mechanisms contributing to vascular dysfunction may also be beneficial $(1,5,6)$. However, the development of improved therapeutic strategies that mitigate diabetic vascular complications has been hampered by an incomplete understanding of molecular mechanisms altering vascular reactivity during diabetes.

Epidemiological and functional studies suggest that, in addition to impaired endothelium-dependent vasodilation, aberrant arterial myocyte contractility contributes to vascular complications, including altered myogenic tone, in diabetic patients and murine models of diabetes (6-11). Functional expression of ion channels - e.g., several types of potassium $\left(\mathrm{K}^{+}\right)$channels and L-type $\mathrm{Ca}_{\mathrm{v}} 1.2$ channels - regulates arterial myocyte excitability and myogenic tone (8). Alterations in the expression and/or function of these channels are associated with enhanced arterial myocyte contractility and myogenic tone during diabetic hyperglycemia (see reviews in refs. $8,11,12$ ). Indeed, we recently reported

Authorship note: AUS, GRR, and DC contributed equally to this work. Conflict of interest: The authors have declared that no conflict of interest exists. Copyright: () 2019, American Society for Clinical Investigation.

Submitted: September 4, 2018; Accepted: May 14, 2019; Published: July 2, 2019. Reference information: / Clin Invest. 2019;129(8):3140-3152.

https://doi.org/10.1172/JCI124705. that L-type $\mathrm{Ca}^{2+}$ channel activity in arterial myocytes is elevated and contributes to endothelium-independent enhancement of myogenic tone during elevated extracellular glucose as well as in diabetes $(13,14)$. This was found to be mediated by phosphorylation of the L-type $\mathrm{Ca}^{2+}$ channel pore-forming $\mathrm{Ca}_{\mathrm{v}} 1.2$ subunit at serine 1928 by the serine/threonine kinase protein kinase A (PKA) $(13,15)$. The observation that glucose could mediate vasoconstriction via a PKA pathway was unexpected as PKA activity has been traditionally linked to vasodilation. Our prior work attributed the PKA-mediated vasoconstriction during elevated glucose to activation of a PKA pool in close proximity to a subpopulation of $\mathrm{Ca}_{\mathrm{v}} 1.2$ (13). Yet the mechanism by which elevated extracellular glucose leads to increased PKA activity is not well understood.

Prior studies in yeast have shown that elevated glucose can activate $\mathrm{G} \alpha_{\mathrm{s}}$ signaling (16). This can stimulate adenylyl cyclase (AC) activity and the production of cAMP and PKA activation. Thus, elevated glucose could act through similar mechanisms in arterial myocytes. Of the 9 membrane-bound AC isoforms (17), AC3, AC5, and AC6 are most abundantly expressed in arterial myocytes (18-20). AC6 and, to some extent, AC3 have been associated with vasodilatory pathways via regulation of $\mathrm{K}^{+}$channels $(18,19)$, but AC5 function is unclear. Here, we show a critical role for AC5 in mediating local cAMP production in response to elevated extracellular glucose. This represents a key signaling module mediating PKA activation and the underlying potentiation of vascular L-type $\mathrm{Ca}^{2+}$ channels and vasoconstriction during hyperglycemia and diabetes.

\section{Results}

Glucose stimulates localized AC-mediated cAMP synthesis in arterial myocytes. Our prior work demonstrated a glucose concentration- 

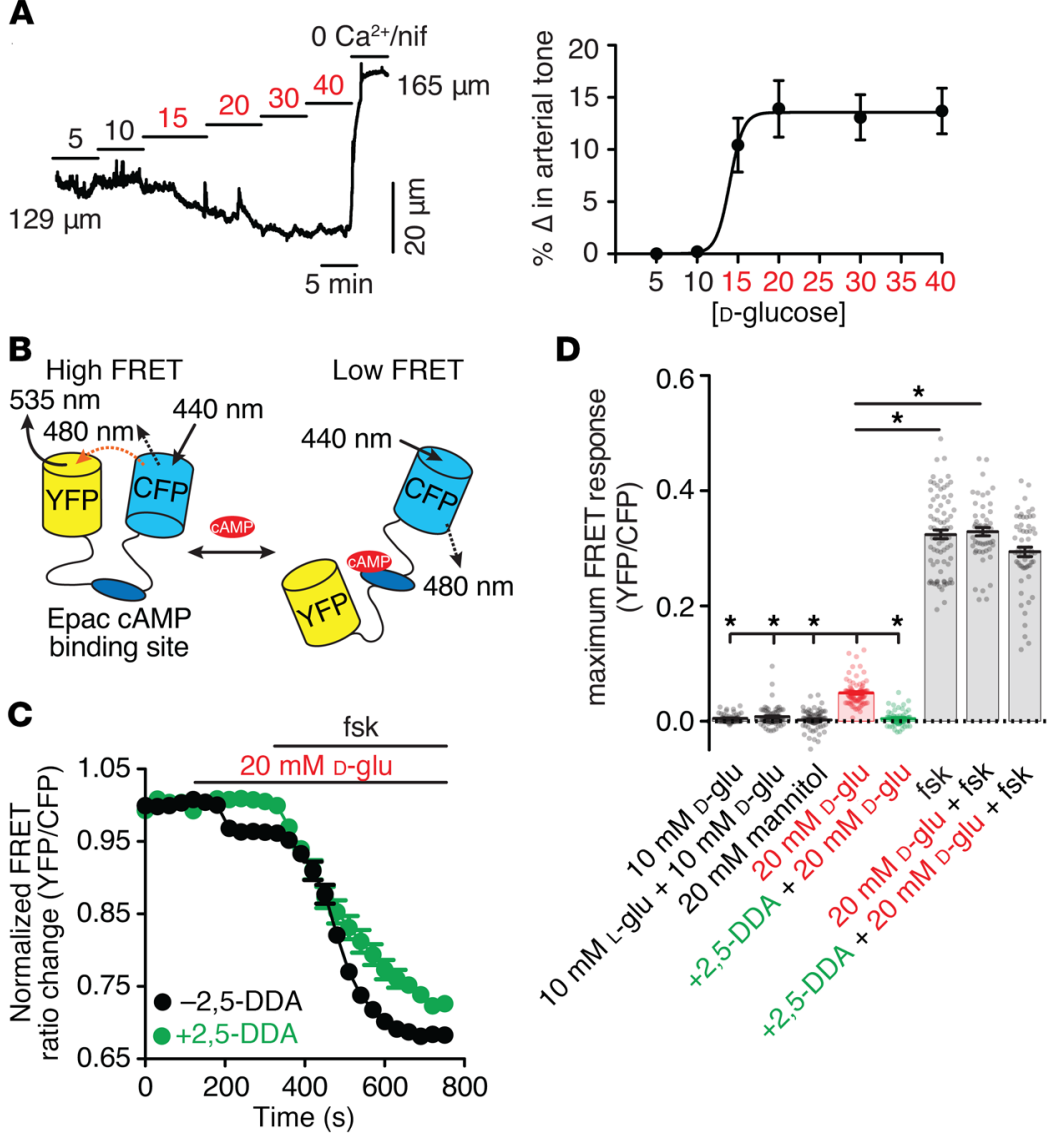

Figure 1. AC activity is required for glucose-induced localized cAMP synthesis in arterial myocytes. (A) Representative diameter recording (left) and summary percent change in arterial tone (right) from pressurized $(60 \mathrm{mmHg}$ ) WT cerebral arteries in response to different extracellular D-glucose concentrations ( $n=6$ arteries from 4 mice). Solid line in the arterial tone/ [D-glucose] graph represents the best fit curve to data using a sigmoidal dose-response equation. The half-maximal o-glucose concentration (i.e., $\mathrm{EC}_{50}$ ) was $14.5 \pm 0.4 \mathrm{mM}$. (B) Schematic showing the design of the Epac1-camps-based FRET sensor (ICUE3). (C) Average ICUE3-PM responses to increases from $10 \mathrm{mM}$ to $20 \mathrm{mM}$ external $\mathrm{D}$-glucose before and after application of forskolin $(1 \mu \mathrm{M})$ in WT arterial myocytes untreated and treated with 2,5-DDA (10 $\mu \mathrm{M})$. The FRET signals were normalized to the yellow fluorescent protein/cyan fluorescent protein ratio observed with $10 \mathrm{mM}$ D-glucose. (D) Plot of maximum FRET response to $10 \mathrm{mM}$ o-glucose ( $n=56$ cells), $10 \mathrm{mM}$ D-glucose $+10 \mathrm{mM}$ L-glucose ( $n=72$ cells), $20 \mathrm{mM}$ mannitol ( $n=76$ cells), $20 \mathrm{mM}$ D-glucose ( $n=91$ cells), $20 \mathrm{mM} \mathrm{D-glucose} \mathrm{in} \mathrm{2,5-DDA-treated} \mathrm{cells} \mathrm{(} n=58$ cells), forskolin ( $1 \mu \mathrm{M} ; n=78$ cells), $20 \mathrm{mM}$ D-glucose $+1 \mu \mathrm{M}$ forskolin ( $n=52$ cells), and $20 \mathrm{mM} \mathrm{D-glucose}$ $+1 \mu \mathrm{M}$ forskolin in 2,5-DDA-treated cells $(n=58$ cells). Experiments from at least 3 different isolations; 3 mice used per isolation. ${ }^{*} P<0.05$, Kruskal-Wallis with Dunn's multiple comparisons. Statistical differences were compared between all data sets, and the asterisk highlights those with significance. Data represent mean \pm SEM.

dependent effect on global intracellular $\mathrm{Ca}^{2+}\left(\left[\mathrm{Ca}^{2+}\right]_{\mathrm{i}}\right)$ in arterial myocytes (14). Consistent with these results, here we found that glucose increases myogenic tone of pressurized $(60 \mathrm{mmHg}$ ) cerebral arteries from WT mice in a concentration-dependent manner with an $\mathrm{EC}_{50}$ of $14.5 \pm 0.4 \mathrm{mM}$ (Figure $1 \mathrm{~A}$ and Supplemental Tables 1 and 2; supplemental material available online with this article; https://doi.org/10.1172/JCI124705DS1). Increasing extracellular glucose from $5 \mathrm{mM}$ to $10 \mathrm{mM}$ had no significant effect on myogenic tone (Supplemental Table 2). Elevating external glucose to $15 \mathrm{mM}$ caused an appreciable but statistically insignificant change in myogenic tone, compared with $5 \mathrm{mM}(P=0.1785)$ and $10 \mathrm{mM}(P=0.2821)$. Yet $20 \mathrm{mM}$ D-glucose evoked a significant change in myogenic tone, compared with 5-10 mM, that was not further raised by 30-40 mM D-glucose (Supplemental Table 2). Glucose-induced constriction was not attributed to changes in osmolarity, as equimolar concentration of nonpermeable mannitol or nonmetabolizable L-glucose had no effects on vascular reactivity $(13,14,21,22)$. Note that the $10 \mathrm{mM}$ and $20 \mathrm{mM}$ D-glucose concentrations are within the range observed for nonfasting control and diabetic mice, respectively, and have been extensively used by us and others as low and high external glucose conditions to examine glucose-mediated remodeling in arterial myocytes $(13,14,21$, 23-28). These findings suggest that changes in external glucose between $10 \mathrm{mM}$ and $20 \mathrm{mM}$ translate into sustained elevations in mouse arterial myocyte global $\left[\mathrm{Ca}^{2+}\right]_{i}$ and myogenic tone, and thus justify their use as control and hyperglycemic conditions, respectively.

We next investigated the effects of acute elevations in extracellular glucose from $10 \mathrm{mM}$ to $20 \mathrm{mM}$ on cAMP synthesis, and the involvement of ACs in this process in arterial myocytes. For these experiments, we used a membranetargeted Epac1-camps-based fluorescence resonance energy transfer (FRET) sensor (ICUE3-PM; Figure 1B and refs. 29, 30). Given the difficulty of overexpressing exogenous proteins, such as the ICUE3-PM, in native tissue, we expressed the sensor in primary, unpassaged arterial myocytes. These cells retained their elongated morphology (Supplemental Figure 1A) and responded to a depolarizing stimulus (i.e., $60 \mathrm{mM}$ extracellular $\mathrm{K}^{+}$) with a robust increase in $\left[\mathrm{Ca}^{2+}\right]_{\mathrm{i}}$ (Supplemental Figure 1B). Flow cytometry data revealed that $96.7 \% \pm 0.7 \%$ of the primary, unpassaged arterial myocytes and $98.7 \% \pm 0.5 \%$ of freshly isolated arterial myocytes were positive for $\alpha$-smooth muscle actin and negative for fibroblast as well as endothelial and lineage markers (Supplemental Figure 1, C-E). These results indicate a high level of purity of our primary, unpassaged arterial myocyte cultures. Proper targeting of the ICUE3-PM was validated by confirmation of its expression at the membrane (by both infection and transfection) as well as the localization of an ICUE3 targeted to the nucleus (ICUE3-NLS) and an endoplasmic reticulum marker, Sec61ß-GFP (Supplemental Figure 2A).

In ICUE3-PM-expressing cells, an increase from $10 \mathrm{mM}$ to 20 $\mathrm{mM}$ D-glucose elicited a subtle yet significant increase in cAMP synthesis, which was further amplified by the broad AC activator forskolin (Figure 1, C and D, and Supplemental Figure 2B). These results are indicative of glucose-induced localized cAMP synthesis. Coapplication of $20 \mathrm{mM}$ D-glucose plus forskolin had no additive effect on cAMP synthesis compared with forskolin alone 
A
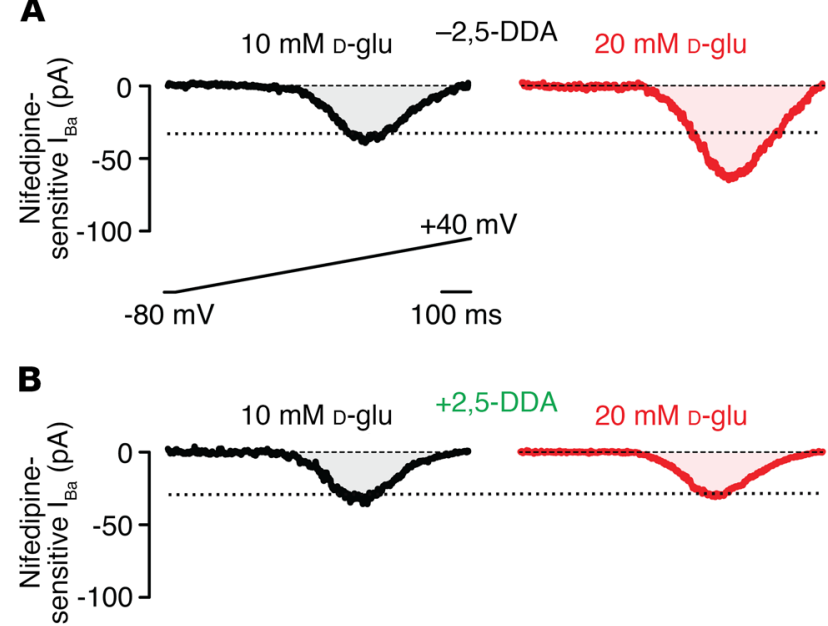

C

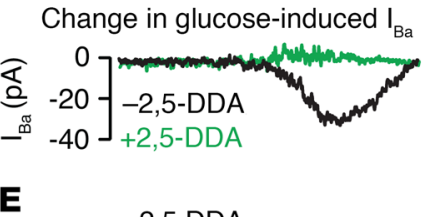

E
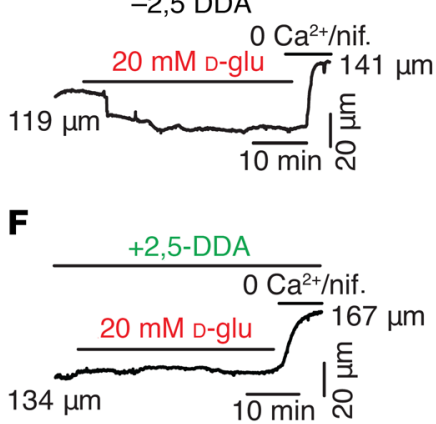

D
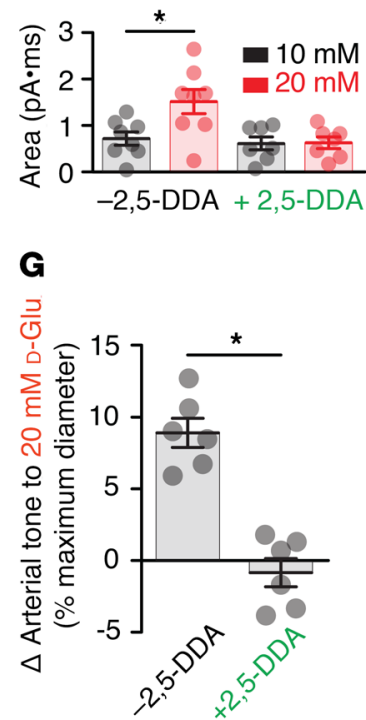

Figure 2. AC activity is required for vascular L-type $\mathbf{C a}^{2+}$ channel potentiation and vasoconstriction in response to increased glucose. (A and $B$ ) Exemplary nifedipine-sensitive $\mathrm{I}_{\mathrm{Ba}}$ from WT arterial myocytes untreated (A) and pretreated with 2,5-DDA (B) in response to a voltage ramp before and after increasing of extracellular glucose from $10 \mathrm{mM}$ to $20 \mathrm{mM}$. (C) Representative $\mathrm{I}_{\mathrm{Ba}}$ traces showing changes in glucose-induced current during a ramp depolarization from $-80 \mathrm{mV}$ to $+40 \mathrm{mV}$ in 2,5-DDA-untreated (-) (black trace) and 2,5-DDA-treated (+) (green trace) cells. (D) Plot (mean \pm SEM) of the integrated area under the curve ( $\mathrm{pA} \cdot \mathrm{ms}$ ) of nifedipine-sensitive $\mathrm{I}_{\mathrm{Ba}}$ recorded in response to a voltage ramp before and after increasing of extracellular glucose from $10 \mathrm{mM}$ to $20 \mathrm{mM}$ in $-2,5$-DDA and $+2,5$-DDA arterial myocytes ( $n=8$ cells from 5 mice for the $-2,5$-DDA group and $n=7$ cells from 3 mice for the $+2,5-$ DDA group). ${ }^{*}<<0.05$, Wilcoxon matched-pairs signed-rank test. Significance was compared between $10 \mathrm{mM}$ and 20 mM D-glucose for each data set. Cell capacitance was similar for the -2,5-DDA (14 $\pm 0.5 \mathrm{pF})$ and $+2,5$-DDA data sets $(15.7 \pm 1.5 \mathrm{pF} ; P=0.5100$, Mann-Whitney test). (E-G) Representative diameter recordings (E and F) and summary plot of changes in arterial tone (G) from pressurized ( $60 \mathrm{mmHg}$ ) WT arteries untreated ( $n=6$ arteries from 6 mice) and pretreated ( $n=6$ arteries from 4 mice) with 2,5-DDA in response to $20 \mathrm{mM}$ D-glucose. ${ }^{*} P<0.05$, Mann-Whitney test. Data represent mean \pm SEM.

(Figure 1D). No change in cAMP synthesis was observed when D-glucose was substituted with equimolar concentrations of the non-metabolizable L-glucose or with the nonpermeable mannitol (Figure 1D), thus ruling out osmolarity effects. These results indicate that glucose needs to be transported into the cell and metabolized in order to trigger cAMP synthesis. Intriguingly, elevated glucose stimulated cAMP synthesis at the plasma membrane, but not in the nuclear region, even though forskolin raised cAMP to about the same level in both compartments (Supplemental Figure 2, C and D). These results suggest distinctive glucose effects on cAMP signaling in different cell regions. In cells treated with the broad AC inhibitor 2',5'-dideoxyadenosine (2,5-DDA), which has nanomolar selectivity for AC5 and AC6 $(31,32)$, glucose-induced cAMP synthesis was prevented and the $20 \mathrm{mM}$ D-glucose plus forskolin effects were slightly reduced, likely owing to inhibition of other AC isoforms (Figure 1, C and D). These results indicate that elevated extracellular glucose stimulates AC-mediated localized cAMP synthesis in arterial myocytes.

$A C$ activity is required for vascular L-type $\mathrm{Ca}^{2+}$ channel potentiation and vasoconstriction during increased extracellular glucose. We tested the hypothesis that AC activity is required for glucoseinduced potentiation of L-type $\mathrm{Ca}^{2+}$ channels and vasoconstriction $(13,14,22)$. For this, we performed voltage ramps using patchclamp electrophysiology with barium $\left(\mathrm{Ba}^{2+}\right)$ as the charge carrier before and after application of nifedipine $(1 \mu \mathrm{M})$ to assess the nifedipine-sensitive $\mathrm{Ba}^{2+}$ current $\left(\mathrm{I}_{\mathrm{Ba}}\right)$ in response to changes in extracellular glucose in freshly dissociated cerebral arterial myocytes. Consistent with prior observations $(13,14,22)$, an increase from $10 \mathrm{mM}$ to $20 \mathrm{mM}$ external D-glucose significantly stimulated $\mathrm{I}_{\mathrm{Ba}}$ (Figure 2, A and D). This outcome is not due to osmotic pressure effects $(13,14,21,22)$. The glucose-mediated increase in $\mathrm{I}_{\mathrm{Ba}}$ was not observed in cells pretreated with the AC inhibitor 2,5-DDA (Figure 2, B and D). Indeed, the involvement of AC in mediating glucose effects on L-type $\mathrm{Ca}^{2+}$ channels can be further appreciated in the representative differential currents in Figure 2C highlighting the voltage-dependency of $\mathrm{I}_{\mathrm{Ba}}$ in response to glucose in the presence and absence of 2,5-DDA.

To assess the physiological relevance of glucose-induced AC activity to vascular reactivity, we measured arterial diameter in pressurized $(60 \mathrm{mmHg})$ middle cerebral arteries isolated from WT mice. We only used arteries that robustly constricted ( $>50 \%$ constriction) in response to the high- $\mathrm{K}^{+}$solution $(60 \mathrm{mM})$ and that spontaneously developed stable tone upon increasing of intravascular pressure to $60 \mathrm{mmHg}$ (Supplemental Tables 3 and 4). Arteries under control conditions constricted significantly in response to elevated external D-glucose (Figure 2E, Supplemental Figure 3A, and Supplemental Tables 3 and 4). This glucose-induced constriction is independent of endothelial function, as similar responses are observed in endothelium-denuded arteries (13). However, glucose-mediated constriction was completely abolished in arteries pretreated with the AC inhibitor 2,5-DDA (Figure 2F, Supplemental Figure 3A, and Supplemental Tables 3 and 4). The change in arterial tone in response to $20 \mathrm{mM}$ D-glucose was significantly larger in control arteries (i.e., -2,5-DDA group) compared with $+2,5$-DDA-treated vessels (Figure 2G). The +2,5-DDA treatment did not modify the vasoconstriction induced by $60 \mathrm{mM} \mathrm{K}^{+}$(Sup- 
A

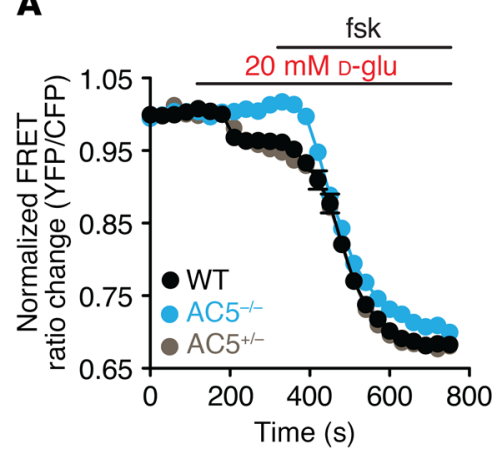

B

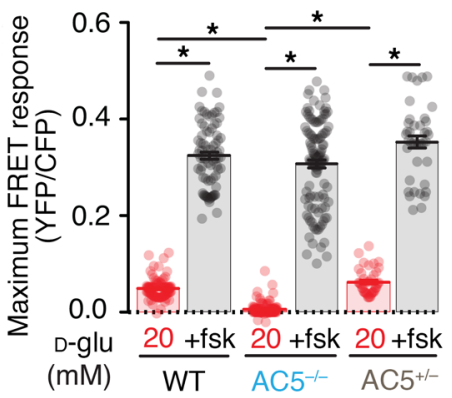

C

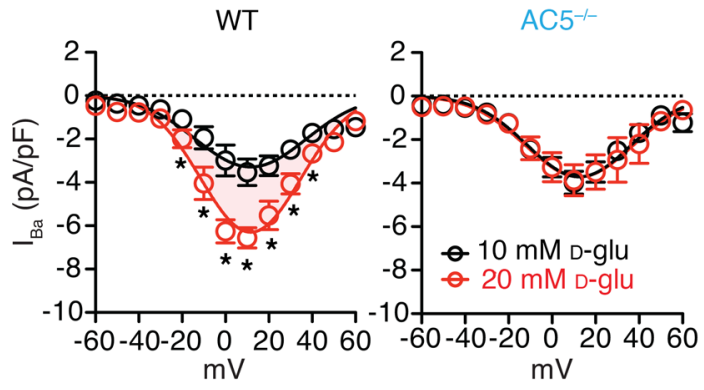

D
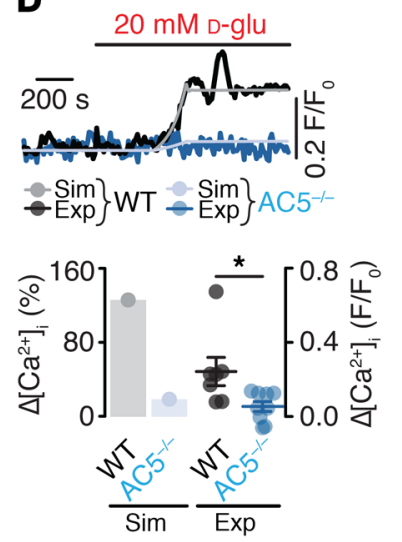

E

\section{$\mathbf{F}$}
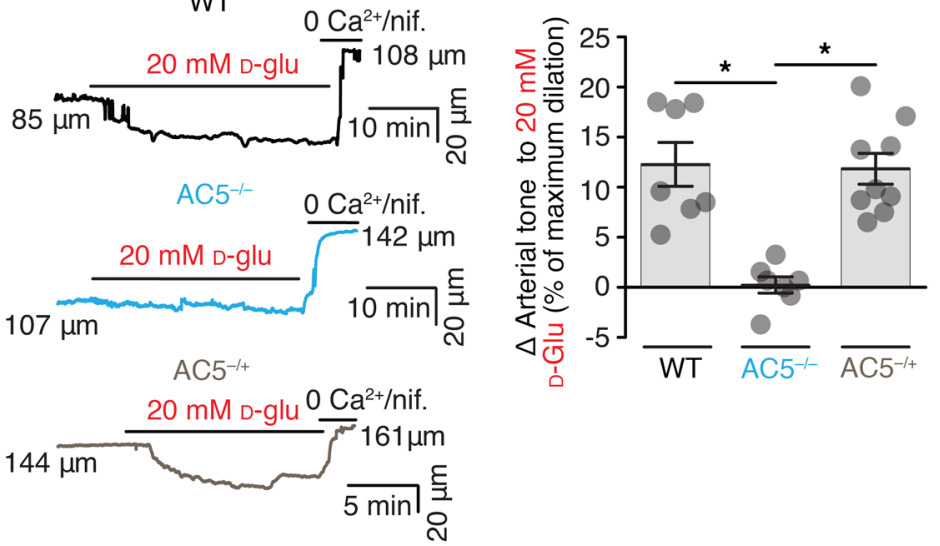

Figure 3. AC5 is necessary for CAMP synthesis, L-type $\mathrm{Ca}^{2+}$ channel potentiation, and vasoconstriction in response to elevated glucose. (A) Averaged ICUE3-PM responses to $20 \mathrm{mM}$-glucose before and after forskolin $(1 \mu \mathrm{M})$ in WT, $\mathrm{AC5} 5^{-1}$, and $\mathrm{AC5}^{-{ }^{+}}$cells. Experiments from at least 3 different isolations, with 3 mice per isolation. (B) Plot of maximum FRET response to $20 \mathrm{mM} \mathrm{D-glucose}$ and $20 \mathrm{mM} \mathrm{D-glucose}+1 \mu \mathrm{M}$ forskolin in WT $(n=92)$, AC5 ${ }^{-1-}(n=114)$, and $\mathrm{AC5}^{-1+}(n=40)$ cells. ${ }^{*} P<0.05$, Kruskal-Wallis test. Significance was compared between the $20 \mathrm{mM}$-glucose and forskolin response and the $20 \mathrm{mM}$ D-glucose response for all conditions. (C) Nifedipine-sensitive $\mathrm{I}_{\text {ва }}$-voltage relationship in WT ( $n=6$ cells) and AC5 ${ }^{-1-}$ ( $n=8$ cells) cells in $10 \mathrm{mM}$ and $20 \mathrm{mM}$ D-glucose. ${ }^{*} P<0.05$, Wilcoxon matched-pairs signed-rank test. Cell capacitance was similar for WT (17.0 $\left.\pm 0.8 \mathrm{pF}\right)$ and $\mathrm{AC5}{ }^{-1-}$ cells $(19.3 \pm 1.9 \mathrm{pF} ; P=0.4700$, Mann-Whitney test). (D) Normalized in silico (sim, light gray and light blue lines) and exemplary experimental (exp, black and blue lines) [C $\left.\mathrm{a}^{2+}\right]_{i}$ traces from arterial myocytes in intact WT and $\mathrm{AC5}^{-1-}$ arteries in response to $20 \mathrm{mM} \mathrm{D-glucose,} \mathrm{and} \mathrm{plot} \mathrm{of} \mathrm{the} \mathrm{percentage} \mathrm{change} \mathrm{in} \mathrm{Ca} \mathrm{a}^{2+}$ in response to $20 \mathrm{mM} \mathrm{D-glucose}$ in WT (from 7 arteries) and AC5 ${ }^{--}$(from 9 arteries) cells $\left({ }^{*} P<0.05\right.$, Mann-Whitney test). (E and $\left.\mathbf{F}\right)$ Representative diameter recordings (E) and summary changes in arterial tone (F) from WT ( $n=7$ arteries from 4 mice), AC5 ${ }^{-/-}\left(n=7\right.$ arteries from 4 mice), and AC5 ${ }^{-{ }^{+}}$( $n=9$ arteries from 4 mice) pressurized arteries in response to $20 \mathrm{mM}$-glucose. ${ }^{*} P<0.05$, Kruskal-Wallis with Dunn's multiple comparisons. Data represent mean \pm SEM.

plemental Table 4) or the magnitude of forskolin-induced vasodilation (Supplemental Figure 3B and Supplemental Tables 3 and 4) in comparison with control arteries. These data suggest that AC activity is required for potentiation of L-type $\mathrm{Ca}^{2+}$ channel activity and vasoconstriction in response to increased glucose.

AC5 is necessary for cAMP synthesis in response to increased extracellular glucose. We sought to define the $\mathrm{AC}$ isoform underlying the glucose effects on cAMP synthesis, PKA-mediated L-type $\mathrm{Ca}^{2+}$ channel activity, and vasoconstriction. Arterial myocytes express several AC isoforms, including AC5 and AC6 $(18,19)$. Given the role of AC6 in vasodilatory pathways (18), we hypothesized a key role for AC5 in mediating the glucose effects on cAMP synthesis. To test this hypothesis, we used arterial myocytes and arteries from age-matched male WT C57BL/6 mice and systemic AC5-knockout $\left(\mathrm{AC}^{-/}\right)$mice that had been backcrossed into the C57BL/6J background for 10 generations (33). Since glucose effects are independent of endothelium $(13,14)$, the use of AC5 $5^{-1-}$ tissue/cells provides relevant insight to support or reject our hypothesis. As an additional control, we generated heterozygous
AC5 $\left(\mathrm{AC5}^{-/+}\right)$mice. The ICUE3-PM sensor was expressed in WT, $\mathrm{AC5}^{-/}$, and $\mathrm{AC5}^{-/+}$arterial myocytes as above. Increasing extracellular D-glucose from $10 \mathrm{mM}$ to $20 \mathrm{mM}$ induced a significant increase in cAMP synthesis in WT and $\mathrm{AC5}^{-/+}$but not in $\mathrm{AC5}^{-/-}$ arterial myocytes (Figure 3, A and B). Yet forskolin application enhanced cAMP synthesis to about the same magnitude in WT, $\mathrm{AC5}^{-/}$, and $\mathrm{AC5}^{-/+}$cells (Figure 3, $\mathrm{A}$ and $\mathrm{B}$ ). These results suggest that AC5 is necessary for glucose-induced cAMP synthesis.

AC5 is required for glucose-induced PKA-mediated L-type $\mathrm{Ca}^{2+}$ channel potentiation and vasoconstriction in ex vivo and in vivo preparations. We tested the hypothesis that increasing extracellular glucose stimulates vascular L-type $\mathrm{Ca}^{2+}$ channel activity in an AC5-dependent manner. To do this, we defined the nifedipinesensitive whole-cell $\mathrm{I}_{\mathrm{Ba}}$ in isolated arterial myocytes. Increasing external D-glucose from $10 \mathrm{mM}$ to $20 \mathrm{mM}$ induced a significant elevation in $\mathrm{I}_{\mathrm{Ba}}$ at multiple membrane potentials with no change in the current-voltage (I-V) relationship $\left(\mathrm{V}_{\text {max }}=14.9 \pm 2.0 \mathrm{mV}\right.$ for $10 \mathrm{mM}$ D-glucose and $\mathrm{V}_{\max }=10.9 \pm 1.1 \mathrm{mV}$ for $20 \mathrm{mM}$ D-glucose; $P=0.1085$, extra sum-of-squares $F$ test) in WT arterial myocytes 
A

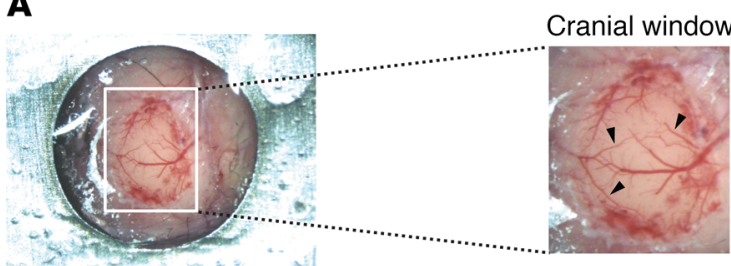

Head plate
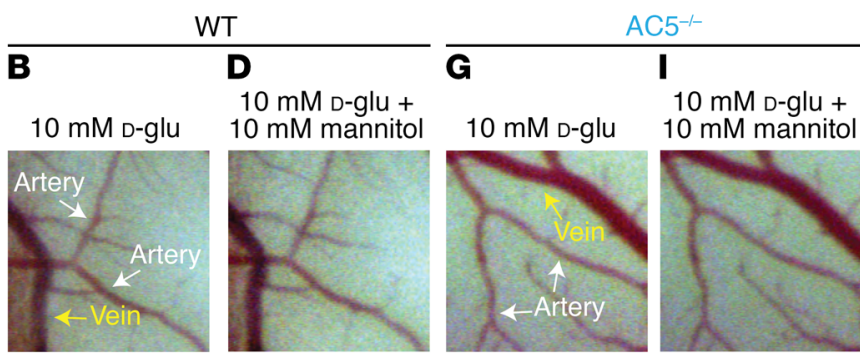

C

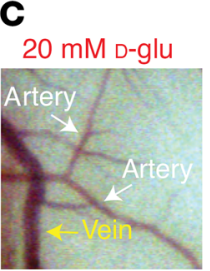

E

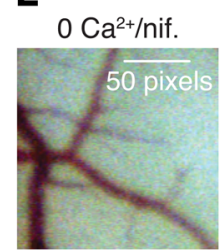

H

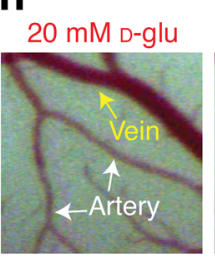

$\mathbf{J}$ $0 \mathrm{Ca}^{2+} / \mathrm{nif}$

F

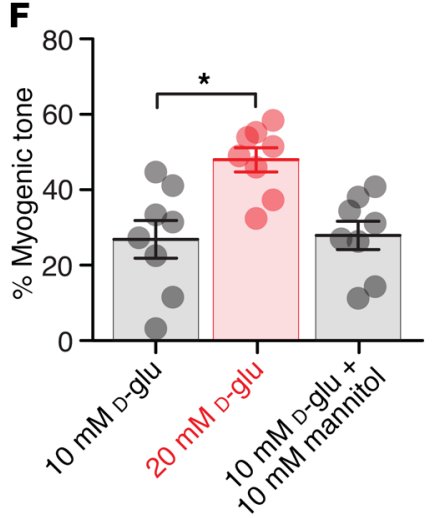

$\mathbf{K}$

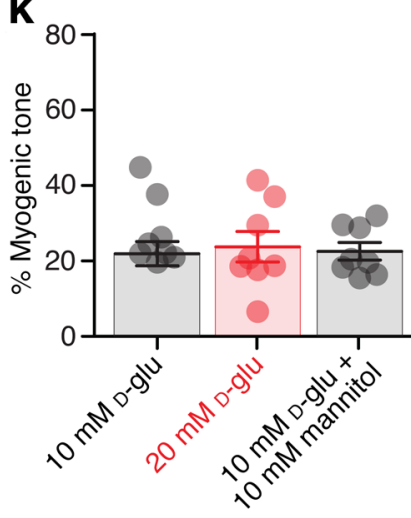

Figure 4. AC5 is necessary for increased myogenic tone of cerebral arteries in response to elevated glucose in vivo. (A) Overview of the open cranial window. Black arrowheads indicate exemplary arteries that were used for analysis. (B-K) Representative images of middle cerebral arteries and branches (white arrows) visualized through an open cranial window and used to analyze diameter changes in response to $10 \mathrm{mM} \mathrm{D-glucose} \mathrm{(B}$ and $\mathbf{G}$ ) and in response to $20 \mathrm{mM}$ o-glucose (C and $\mathbf{H}), 10 \mathrm{mM}$ o-glucose + $10 \mathrm{mM}$ mannitol ( $\mathbf{D}$ and $\mathbf{I}$ ), and $\mathrm{O} \mathrm{Ca}^{2+}+1 \mu \mathrm{M}$ nifedipine ( $\mathbf{E}$ and $\left.\mathbf{J}\right)$ in WT and $\mathrm{AC5}^{-1-}$ mice ( $n=8$ arteries from 2 mice per group). The yellow arrows point to veins. ( $\mathbf{F}$ and $\mathbf{K}$ ) Summary percent myogenic tone in response to $10 \mathrm{mM}$ D-glucose, $10 \mathrm{mM}$ o-glucose $+10 \mathrm{mM}$ mannitol, and $20 \mathrm{mM}$ D-glucose. ${ }^{*} P<$ 0.05 , ANOVA with Tukey's multiple-comparisons test for each group. Data represent mean \pm SEM.

(Figure 3C and Supplemental Figure 4A). In stark contrast, $20 \mathrm{mM}$ D-glucose failed to stimulate L-type $\mathrm{Ca}^{2+}$ channel activity in $\mathrm{AC}^{-/-}$ arterial myocytes (Figure 3C and Supplemental Figure 4A). Note that $\mathrm{I}_{\mathrm{Ba}}$ under control conditions (i.e., $10 \mathrm{mM}$ D-glucose) was similar between WT and $\mathrm{AC5}^{-/-}$cells (WT, $-3.3 \pm 0.2 \mathrm{pA} / \mathrm{pF}$, vs. $\mathrm{AC5}^{-/-}$, $-3.7 \pm 0.2 \mathrm{pA} / \mathrm{pF} ; P=0.1673$, extra sum-of-squares $F$ test). Thus, the lack of $\mathrm{I}_{\mathrm{Ba}}$ response to increased glucose in $\mathrm{AC5}^{-/-}$arterial

myocytes is unlikely to be due to changes in $\mathrm{Ca}_{\mathrm{v}} 1.2$ functional expression. These results suggest an essential role for AC5 in PKA-dependent L-type $\mathrm{Ca}^{2+}$ channel stimulation during elevated extracellular glucose.

We used a well-established mathematical model of arterial myocyte electrophysiology and $\mathrm{Ca}^{2+}$ dynamics (34), recently adapted by us (15), to examine the effects of increased extracellular glucose in modulating arterial myocyte membrane potential $\left(\mathrm{E}_{\mathrm{m}}\right)$ and global $\left[\mathrm{Ca}^{2+}\right]_{\mathrm{i}}$. The model was informed by available data from our group and others indicating that glucose targets both L-type $\mathrm{Ca}^{2+}$ and $\mathrm{K}^{+}$channels to enhance L-type $\mathrm{Ca}^{2+}$ currents and suppress $\mathrm{K}^{+}$currents $(13,14,21,24,28,35,36)$, which are major ionic conductances influencing arterial myocyte excitability (8). Under these conditions, the model predicted that a $10 \mathrm{mM}$ to 20 $\mathrm{mM}$ change in external $\mathrm{D}$-glucose will cause membrane potential depolarization (from $-59 \mathrm{mV}$ to $-52 \mathrm{mV}$ ) and elevate global $\left[\mathrm{Ca}^{2+}\right]_{\mathrm{i}}$ (from $70 \mathrm{nM}$ to $159 \mathrm{nM}$ ) in a simulated WT cell (Supplemental Figure 4B). This approximately 7-mV shift in $\mathrm{E}_{\mathrm{m}}$ and magnitude of change in $\left[\mathrm{Ca}^{2+}\right]_{\mathrm{i}}$ are similar to those previously reported in response to increased external glucose in arterial myocytes $(13-15,24)$. However, when simulating an $\mathrm{AC}^{-/-}$arterial myocyte (or WT cells treated with +2,5-DDA) under basal conditions, the model predicted a more depolarized $\mathrm{E}_{\mathrm{m}}$ and higher $\left[\mathrm{Ca}^{2+}\right]_{\mathrm{i}}$ in comparison with a WT cell (Supplemental Figure 4B). The model also projected that elevating glucose in our simulated $\mathrm{AC}^{-/}$cell would still induce membrane potential depolarization (from $-53 \mathrm{mV}$ to $-49 \mathrm{mV}$ ), albeit of smaller magnitude than in a WT cell. Yet the glucose-induced change in global $\left[\mathrm{Ca}^{2+}\right]_{\mathrm{i}}$ observed in the WT cell will be hindered in the $\mathrm{AC5}^{-/}$cell (from $83 \mathrm{nM}$ to $99 \mathrm{nM}$ ) (Figure 3D and Supplemental Figure 4B). Consistent with these predictions, we experimentally observed a significant increase in global $\left[\mathrm{Ca}^{2+}\right]_{i}$ in arterial myocytes exposed to elevated glucose in pressurized arteries from WT but not $\mathrm{AC}^{-/-}$mice, irrespectively of any potential change in $\mathrm{E}_{\mathrm{m}}$ (Figure $3 \mathrm{D}$ and Supplemental Figure $4 \mathrm{~B}$ ). Altogether, these results suggest a critical role for AC5 activity in stimulating L-type $\mathrm{Ca}^{2+}$ channel activity and global $\left[\mathrm{Ca}^{2+}\right]_{\mathrm{i}}$ during elevated extracellular glucose, independent of changes in membrane potential.

To assess the role of AC5 in modulating vascular reactivity upon increased extracellular glucose, arterial diameter was measured ex vivo in pressurized $(60 \mathrm{mmHg})$ middle cerebral arteries from $\mathrm{WT}, \mathrm{AC5}^{-/-}$, and $\mathrm{AC5}^{-/+}$mice. Arteries from $\mathrm{WT}$ and $\mathrm{AC}^{-/+}$mice developed spontaneous stable tone and exhibited robust constriction in response to elevation in extracellular glucose from $10 \mathrm{mM}$ to $20 \mathrm{mM}$ (Figure 3, E and F, Supplemental Figure 5A, and Supplemental Tables 5 and 6). The response to increased glucose was completely abolished in arteries from $\mathrm{AC}^{-/-}$mice. Peak constriction in response to a $60-\mathrm{mM} \mathrm{K}^{+}$stimulus was similar in $\mathrm{WT}, \mathrm{AC5} 5^{-/+}$, and $\mathrm{AC5} 5^{-/}$arteries (Supplemental Tables 5 and 6), indicating that genetic ablation of AC5 does not inhibit vasoconstriction. Moreover, forskolin application induced vasodilation to a similar extent, even in the presence of elevated glucose, in $\mathrm{WT}, \mathrm{AC}^{-/+}$, and $\mathrm{AC}^{-/}$arteries (Supplemental Figure 5B and Supplemental Tables 5 and 6). Conversely, arteries from AC6-knockout (AC6 ${ }^{-/}$) mice robustly constricted in response to elevated extracellular glucose (Supplemental Figure 5C and Supplemental Tables 5 and 6), suggesting 
A
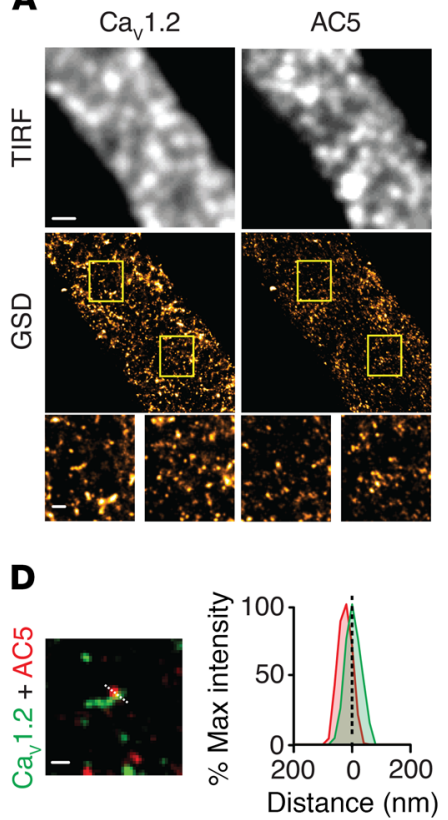
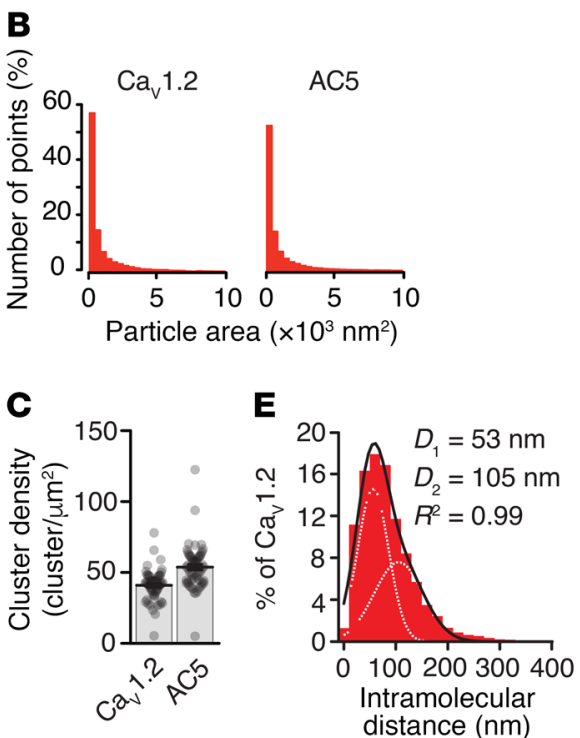

$\mathbf{F}$

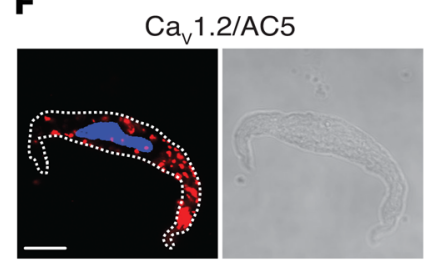

G
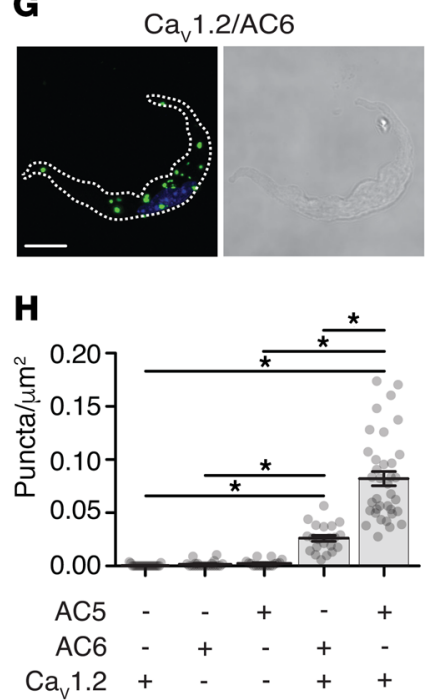

Figure 5. Close association between L-type $\mathrm{Ca}^{2+}$ channel $\mathrm{Ca}_{\mathrm{v}} \mathbf{1 . 2}$ and $\mathrm{AC5}$ in arterial myocytes. (A) Exemplary TIRF images (top panels) and corresponding GSD reconstruction maps (middle panels) from a WT arterial myocyte labeled for $\mathrm{Ca}_{\mathrm{v}} 1.2$ and AC5 (scale bar: $1 \mu \mathrm{m}$ ). Higher magnifications of the areas in the yellow boxes are shown in the bottom panels (scale bar: $200 \mathrm{~nm}$ ). (B) Histograms of the area of clusters of $\mathrm{Ca}_{\mathrm{v}} 1.2$ and AC5 in arterial myocytes ( $n=7$ cells). (C) Plot of the cluster density of Cav 1.2 and AC5 in arterial myocytes ( $n=7$ cells). (D) Higher magnification of a merged image and associated $x-y$ fluorescence intensity profile of areas of close association between $\mathrm{Ca}_{\mathrm{v}} 1.2$ (green) and AC5 (red) (scale bar: $100 \mathrm{~nm}$ ). (E) Histogram of the lowest intermolecular distance to AC5 centroids for $\mathrm{Ca}_{\mathrm{v}} 1.2$ particles. Data were fit with a multi-Gaussian function ( $n=30,141$ particles from 7 cells). (F and $\left.\mathbf{G}\right)$ Exemplary differential interference contrast (right panels) and confocal PLA/DAPI images (left panels) (scale bars: $10 \mu \mathrm{m}$ ) of arterial myocytes colabeled for Ca 1.2 and AC5 (F) and $\mathrm{Ca}_{\mathrm{v}} 1.2$ and AC6 (G). (H) Quantification of PLA puncta per square micrometer cell area for isolated arterial myocytes labeled with Ca $1.2(n=21$ cells), AC5 ( $n=18$ cells), AC6 ( $n=22$ cells), Ca $1.2+$ AC5 ( $n=36$ cells), or Ca $1.2+$ AC6 $\left(n=21\right.$ cells). ${ }^{*} P<0.05$, Kruskal-Wallis with Dunn's multiple comparisons. Significance was compared between data sets as specified. Data represent mean SEM.

that AC6 plays no significant role in this process. Indeed, the magnitude of the glucose-mediated constriction was similar between WT and $\mathrm{AC6}^{-/-}$arteries (WT, 28.1\% $\pm 2.7 \%$, vs. $\mathrm{AC6}^{-/-}, 23.1 \% \pm$ $4.2 \% ; P=0.260$, Mann-Whitney test).

We also evaluated the glucose effects on vascular reactivity in vivo using an open cranial window in anesthetized mice (Figure 4A). This approach exposes middle cerebral arteries and branches to topical treatment. Permeation of the cranial window with a 20-mM D-glucose solution induced a robust sustained constriction of cerebral arteries in WT mice (Figure 4, B, C, F, and Supplemental Tables 7 and 8). As expected, application of a solution containing $\mathrm{O} \mathrm{Ca}^{2+}$ and the L-type $\mathrm{Ca}^{2+}$ channel blocker nifedipine $(1 \mu \mathrm{M})$ caused dilation of the arteries (Figure $4 \mathrm{E}$ ). Myogenic tone increased from $26.0 \% \pm 5.0 \%$ in $10 \mathrm{mM}$ D-glucose to $47.4 \% \pm 3.2 \%$ in $20 \mathrm{mM}$ D-glucose (normalized to $0 \mathrm{Ca}^{2+} /$ nifedipine; $P<0.05$; Figure $4 \mathrm{~F}$ and Supplemental Tables 7 and 8). Note that no change in myogenic tone was observed when D-glucose was substituted with equimolar concentrations of the nonpermeable mannitol, ruling out any osmotic pressure effects in this preparation (Figure 4, D and F, and Supplemental Tables 7 and 8). In contrast, we found no change in myogenic tone upon elevating extracellular
D-glucose from $10 \mathrm{mM}(27.1 \% \pm 3.2 \%)$ to $20 \mathrm{mM}(23.6 \% \pm 4.1 \%$; $P=0.3663$, ANOVA with Tukey's multiple-comparisons test) in arteries from $\mathrm{AC}^{-/-}$mice (Figure 4, G-K, and Supplemental Tables 7 and 8). These results suggest that AC5 is necessary for glucoseinduced vasoconstriction in vivo. Altogether, our data indicate that elevated extracellular glucose triggers localized AC5-dependent cAMP synthesis that leads to PKA-mediated potentiation of vascular L-type $\mathrm{Ca}^{2+}$ channel activity and vasoconstriction.

Close association of L-type $\mathrm{Ca}^{2+}$ channel $\mathrm{Ca}_{V} 1.2$ and AC5 in arterial myocytes. We hypothesized that a subpopulation of AC5 is in close proximity to the L-type $\mathrm{Ca}^{2+}$ channel pore-forming subunit $\mathrm{Ca}_{\mathrm{v}} 1.2$ in arterial myocytes to enable functional regulation of channel activity by glucose. To test this possibility, we used ground state depletion (GSD) super-resolution nanoscopy in the total internal reflection fluorescence (TIRF) configuration with antibodies specific for $\mathrm{Ca}_{\mathrm{v}} 1.2$ and $\mathrm{AC}$. The $\mathrm{Ca}_{\mathrm{v}} 1.2$ antibody has been extensively validated by our group $(13,37)$. The AC5 antibody was validated by Western blot analysis and immunofluorescence imaging with whole-brain lysates and isolated arterial myocytes, respectively, from WT and $\mathrm{AC}^{-/-}$mice (Supplemental Figure 6). Note that protein expression and AC5- 
A

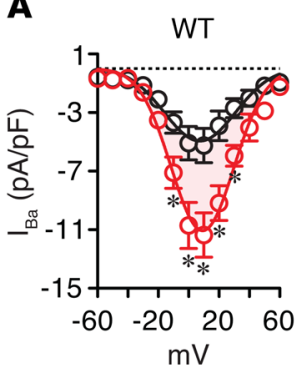

B

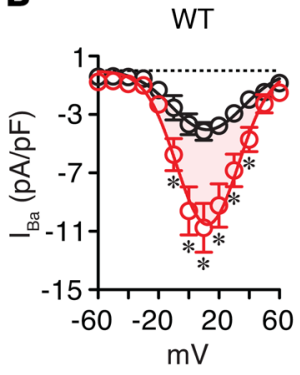

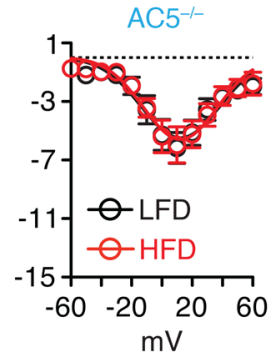

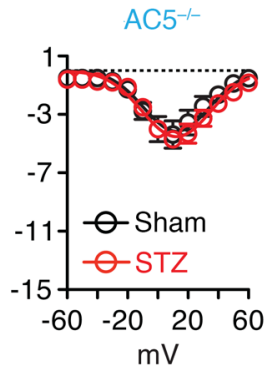

C

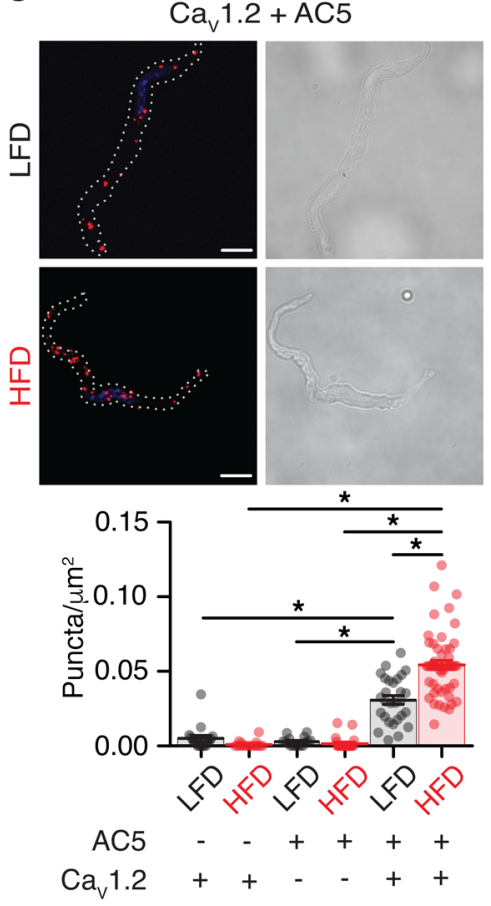

D

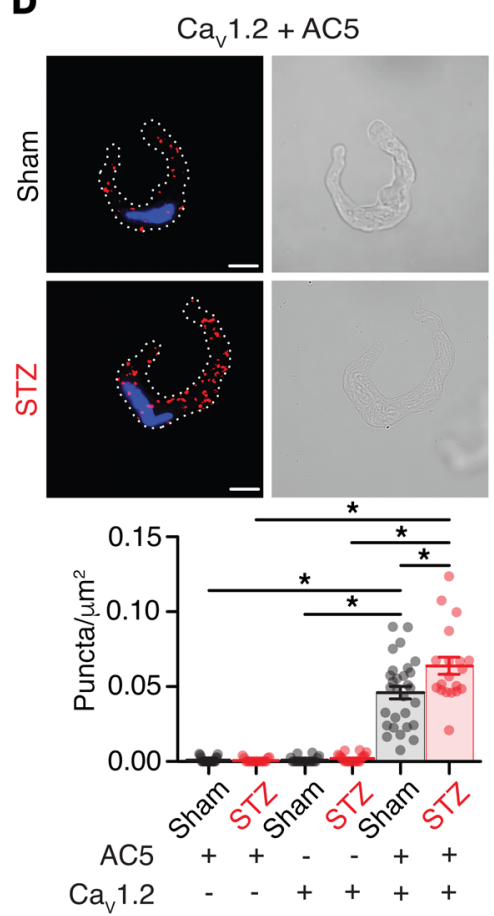

Figure 6. AC5 expression is critical for increased L-type $\mathrm{Ca}^{2+}$ channel activity in HFD and STZ arterial myocytes. (A) $I_{B \mathrm{~B}}$-voltage relationship from LFD and HFD WT cells (LFD capacitance $=17.0 \pm 0.6 \mathrm{pF}, n=8$ cells $/ 4$ mice; HFD capacitance $=15.7 \pm 0.5 \mathrm{pF}, n=7$ cells $/ 4$ mice) and AC5 $5^{-/-}$cells (LFD capacitance $=16.2$ $\pm 1.0 \mathrm{pF}, n=8$ cells $/ 4$ mice; HFD capacitance $=16.4 \pm 0.8 \mathrm{pF}, n=8$ cells $/ 4$ mice). ${ }^{*} P<0.05$, Mann-Whitney test. I-V relationship was similar between LFD and HFD WT cells (LFD V $\max =7.4 \pm 2.1 \mathrm{mV}$ vs. HFD V ${ }_{\max }=9.2 \pm 1.2 \mathrm{mV} ; P=0.4847$, extra sum-of-squares $F$ test) and $A C 5^{-1-}$ cells (LFD V max $=11.9 \pm 2.3 \mathrm{mV}$ vs. HFD $\mathrm{V}_{\max }=12.4 \pm 2.1 \mathrm{mV} ; P=0.3489$, extra sum-of-squares $F$ test). (B) $\mathrm{I}_{\mathrm{Ba}}$-voltage relationship from sham and STZ WT cells (sham capacitance $=16.8 \pm 1.5 \mathrm{pF}$, $n=10$ cells $/ 4$ mice; STZ capacitance $=17.6 \pm 1.4 \mathrm{pF}, n=9$ cells $/ 4$ mice) and AC5 ${ }^{-1-}$ cells (sham capacitance $=16.0 \pm 1.6 \mathrm{pF}, n=7$ cells $/ 4$ mice; STZ capacitance $=15.0 \pm 0.7 \mathrm{pF}, n=12$ cells $/ 5$ mice). ${ }^{*} P<0.05$, Mann-Whitney test. I-V relationship was similar between sham and STZ WT cells (sham $V_{\max }=13.1 \pm 1.8 \mathrm{mV}$ vs. $S T Z V_{\max }=12.3 \pm 1.4 \mathrm{mV} ; P=0.7992$, extra sum-of-squares $F$ test) and $A C 5^{-1-}$ cells (sham $V_{\max }=9.5 \pm 1.9 \mathrm{mV}$ vs. $S T Z V_{\max }=13.6 \pm 1.3 \mathrm{mV} ; P=0.0789$, extra sum-of-squares $F$ test). (C and D) Exemplary confocal PLA and differential interference contrast images of LFD and HFD (C) and sham and STZ (D) WT cells colabeled for $\mathrm{Ca}_{\mathrm{v}} 1.2$ and AC5 (scale bars: $\left.10 \mu \mathrm{m}\right)$. Plot of PLA fluorescent puncta/ $\mu \mathrm{m}^{2}$ cell area for WT LFD and HFD cells (C; $n=17-52$ cells per condition; ${ }^{*} P<0.05$, Kruskal-Wallis test with comparisons between data sets as specified) and sham and STZ cells ( $\mathbf{D} ; n=17-29$ cells per condition; ${ }^{*} P<0.05,1$-way ANOVA for comparisons between experimental and negative control data sets, Mann-Whitney test for comparison between experimental sham and STZ) labeled for $A C 5, C a_{v} 1.2$, and $A C 5+C a_{v} 1.2$. Data represent mean $\pm S E M$.

associated fluorescence were completely absent in brain protein lysates and arterial myocytes, respectively, from $\mathrm{AC}^{-/-}$animals. These results also confirm expression of AC5 in arterial myocytes. Whereas conventional TIRF images showed diffuse fluorescence associated with $\mathrm{Ca}_{\mathrm{v}} 1.2$ and AC5, the GSD-rendered localization maps revealed broad distribution of both proteins in clusters of variable sizes $\left(\mathrm{Ca}_{\mathrm{v}} 1.2,2764 \pm 138 \mathrm{~nm}^{2}\right.$; AC5, 3205 $\pm 170 \mathrm{~nm}^{2}$; Figure 5, A and B) and cluster densities (Figure 5C) throughout the plasma membrane of arterial myocytes. The $\mathrm{Ca}_{\mathrm{v}} 1.2$ - and AC5-associated fluorescent signals and distributions were never observed in cells in which primary antibodies were omitted (Supplemental Figure 7A) or nonimmune IgGs were used (Supplemental Figure 7B). Upon closer inspection, we noticed sites of close interaction between $\mathrm{Ca}_{\mathrm{v}} 1.2$ and AC5 (Figure 5D). Nearest-neighbor analysis between $\mathrm{Ca}_{\mathrm{v}} 1.2$ and AC5 showed, on average, 2 components with centers at approximately 53 and $105 \mathrm{~nm}$ (Figure 5E). In stark contrast, GSD nanoscopy with nearest-neighbor analysis revealed that clusters of $\mathrm{Ca}_{\mathrm{v}} 1.2$ and transferrin receptor ( $\mathrm{TfR}$ ), which has limited to no interaction with $\mathrm{Ca}_{\mathrm{v}} 1.2(13,38)$, were further apart from each other and had a broader distance distribution (Supplemental Figure
7, C-E). The closer average distance component between $\mathrm{Ca}_{\mathrm{v}} 1.2$ and TfR was $110 \mathrm{~nm}$, compared with $55 \mathrm{nM}$ for $\mathrm{Ca}_{\mathrm{v}} 1.2$ and AC5, with most TfR clusters more than $500 \mathrm{~nm}$ apart from $\mathrm{Ca}_{\mathrm{v}} 1.2$ (Supplemental Figure 7E).

We complemented the GSD results with the proximity ligation assay (PLA), which detects whether 2 proteins of interest are at or less than $40 \mathrm{~nm}$ apart (39). We have extensively validated this approach $(9,13,22)$. Robust PLA signal was observed in cells colabeled for $\mathrm{Ca}_{\mathrm{v}} 1.2$ and AC5 (Figure 5, F and H). This PLA signal was nearly absent when either primary antibody for $\mathrm{Ca}_{\mathrm{v}} 1.2$ or AC5 was omitted (Figure $5 \mathrm{H}$ and Supplemental Figure $7 \mathrm{~F})$. We also examined the association between $\mathrm{Ca}_{\mathrm{v}} 1.2$ and AC6. Although PLA signal was detected between $\mathrm{Ca}_{\mathrm{v}} 1.2$ and AC6 (Figure 5, G and H, and Supplemental Figure 7F), their density was significantly lower than that observed for $\mathrm{Ca}_{\mathrm{v}} 1.2$ and AC5 (Figure $5 \mathrm{H})$. Altogether, these results indicate a close association $(\leq 40$ $\mathrm{nm}$ ) between pools of $\mathrm{Ca}_{\mathrm{v}} 1.2$ and AC5 in arterial myocytes.

AC5 depletion prevents vascular L-type $\mathrm{Ca}^{2+}$ channel activity and myogenic tone remodeling in HFD and STZ mice. L-type $\mathrm{Ca}^{2+}$ channel activity and myogenic tone are elevated during diabetes $(13,14,27,28,40,41)$. To explore the involvement of AC5 in 
A

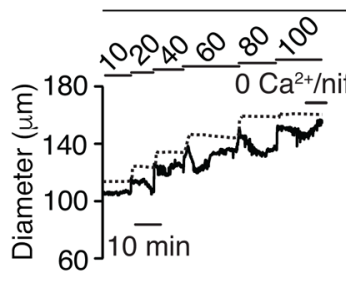

B

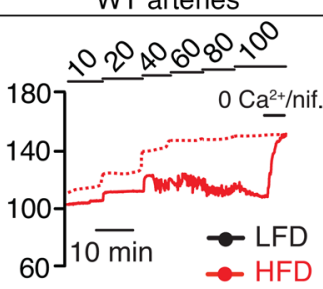

$\mathrm{AC5}^{-1-}$ arteries

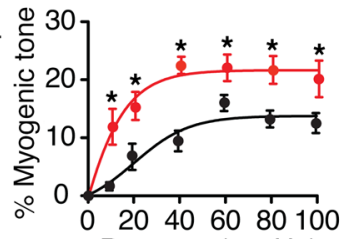

Pressure $(\mathrm{mmHg})$
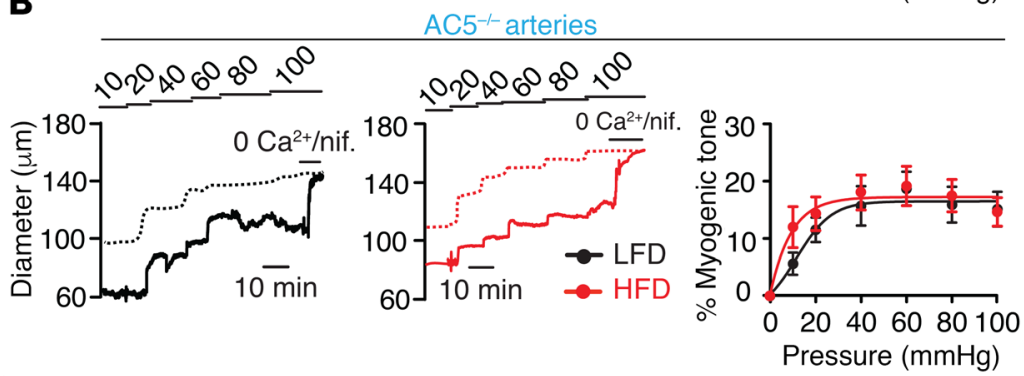

C
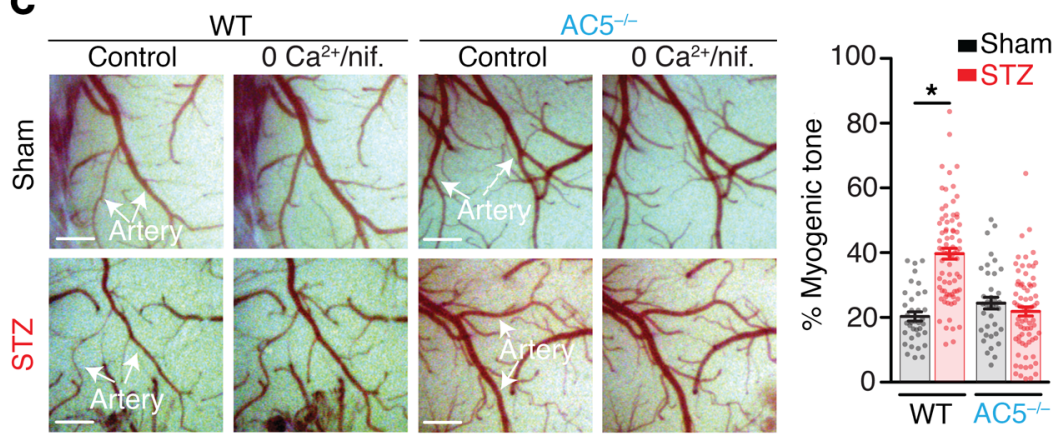

Figure 7. AC5 expression mediates increased myogenic tone in HFD and STZ arteries in ex vivo and in vivo preparations. Exemplary diameter recordings over a pressure range (from 10 to $100 \mathrm{mmHg}$ ) and plot summarizing percent myogenic tone obtained using arteries from WT mice (A; LFD: $n=6$ arteries from 6 mice; HFD: $n=6$ arteries from 5 mice) and AC5 ${ }^{-/-}$mice (B; LFD: $n=5$ arteries from 5 mice; HFD: $n=6$ arteries from 6 mice) on LFD and HFD ( ${ }^{*} P<$ 0.05 , Mann-Whitney test). Dashed lines represent passive diameter. (C) Representative images of middle cerebral arteries and branches (white arrows) visualized through an open cranial window from sham- and STZ-treated WT mice $(n=36$ arteries from 5 mice for sham and $n=77$ arteries from 6 mice for STZ) and AC5 ${ }^{-1-}$ mice ( $n=38$ arteries from 4 mice for sham and $n=73$ arteries from 7 mice for STZ). The right panel shows a plot of percent myogenic tone from sham- and STZ-treated WT and AC5 ${ }^{-1-}$ mice. ${ }^{*} P<0.05$, Mann-Whitney test between data sets from the same genotype. Data represent mean \pm SEM.

this remodeling, we used 2 well-established models of diabetes. The first is a diet-induced diabetic mouse model that recapitulates clinical features observed in type 2 diabetic patients $(13,21,28,42-47)$. The second is the streptozotocin-induced (STZ-induced) diabetic mouse model (48). For both animal models, age-matched male $\mathrm{WT}$ and $\mathrm{AC}^{--}$mice were used. The C57BL/6J is a suitable background for examining dietinduced metabolic disorders $(47,49)$. WT and $\mathrm{AC5}^{-/}$mice were fed a low-fat diet (LFD; 10\% kcal fat) or a high-fat diet (HFD; $60 \% \mathrm{kcal}$ fat) with the same composition and formulation (except for fat content) for 12-16 weeks $(13,28,42,44)$. This is critical as differences in diets' composition and formulation as well as inappropriate use of grain-based chow as a "control diet" will have confounding effects associated with other components present in the diets $(47,50)$. We have extensively used this model in previous studies to examine remodeling of different ion channels (including L-type $\mathrm{Ca}^{2+}$ channels) and transcription factors as well as vascular reactivity, and results have been positively correlated with changes observed in arteries/ arterial myocytes from diabetic patients $(9,13$, $21,28)$. Independently, $\mathrm{WT}$ and $\mathrm{AC5}^{-/-}$mice were injected with either control citrate buffer (i.e., sham) or STZ. Body weight, nonfasting blood glucose levels, and cholesterol were significantly increased in HFD mice compared with LFD animals (Supplemental Table 9). Intriguingly, a previous report suggested that genetic ablation of AC5 was protective against obesity, glucose intolerance, and insulin resistance (51), which contrasts with our observations in the HFD model (Supplemental Table 9). These disparities can be accounted for by several key experimental differences between the studies, including differences in genetic background and use of appropriate control diet and HFD composition and formulation. We also observed the characteristic increase in nonfasting blood glucose levels with a slight loss in weight in STZ mice compared with sham (Supplemental Table 10). Arteries and arterial myocytes from these mice were isolated, maintained, and experimented upon using solutions with $10 \mathrm{mM}$ D-glucose.

Arterial myocytes from WT but not $\mathrm{AC}^{-/-}$mice in HFD (Figure 6A and Supplemental Figure 8A) and STZ (Figure 6B and Supplemental Figure 8B) showed a significant increase in $\mathrm{I}_{\mathrm{Ba}}$ over several membrane potentials with no change in the $\mathrm{I}-\mathrm{V}$ relationship, compared with corresponding controls (for details see legend to Figure 6, A and B). The potentiation of $\mathrm{I}_{\mathrm{Ba}}$ in WT HFD and STZ cells was correlated with increased association between $\mathrm{Ca}_{\mathrm{v}} 1.2$ and $\mathrm{AC} 5$ in HFD (Figure 6C and Supplemental Figure 8C) and STZ (Figure 6D and Supplemental Figure 8C) arterial myocytes, compared with LFD and sham cells, respectively, as assessed with PLA. Vasoconstriction in response to $60 \mathrm{mM} \mathrm{K}^{+}$ was significantly higher in arteries from WT HFD mice, but not in arteries from $\mathrm{AC}^{-/-}$mice, compared with corresponding LFD arteries (Supplemental Tables 11 and 12). Myogenic tone at several intravascular pressures was significantly elevated in arteries from WT mice on HFD compared with the LFD cohort (Figure 7A and Supplemental Tables 11 and 12). In stark contrast, myogenic tone was similar in cerebral arteries from $\mathrm{AC}^{-/-}$mice on LFD or HFD (Figure 7B and Supplemental Tables 11 and 12). Similarly, in vivo intravital imaging of cerebral arteries using a cranial window revealed increased myogenic tone in WT STZ mice compared with WT sham (Figure 7C and Supplemental Tables 13 and 14). The myogenic tone of cerebral arteries in sham- and STZ-treated $\mathrm{AC5}^{-/-}$mice was similar between each other and the WT sham group. Collectively, these data indicate a key role for AC5 in mediating increased L-type $\mathrm{Ca}^{2+}$ channel activity and myogenic tone in HFD and STZ mice. 


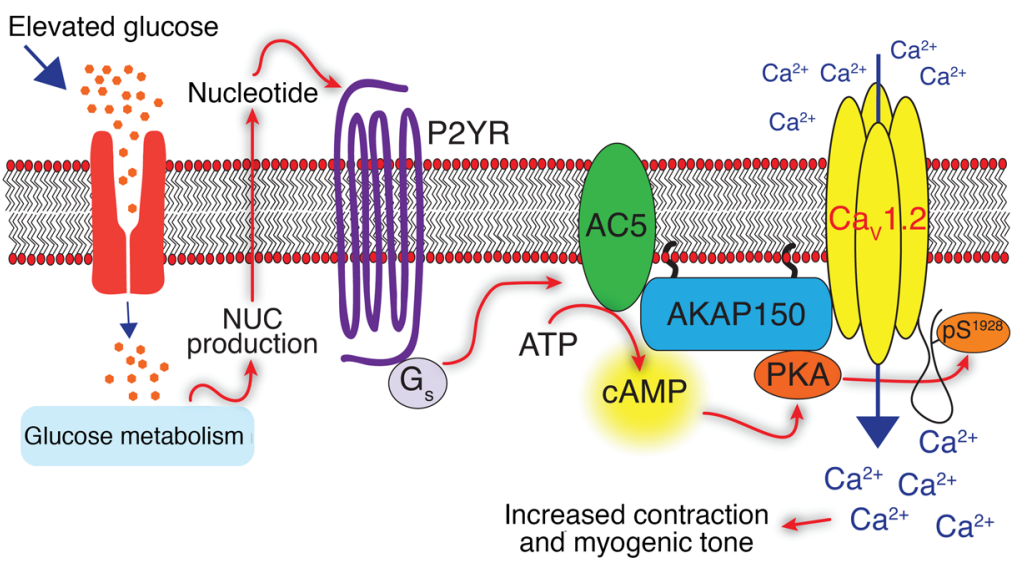

Figure 8. Proposed model for role of AC5-mediated localized cAMP production in stimulation of $\mathrm{L}$-type $\mathrm{Ca}^{2+}$ channels and vasoconstriction upon increases in extracellular glucose and in diabetes. Schematic model of glucose-mediated, AC5-dependent regulation of L-type $\mathrm{Ca}^{2+}$ channel activity and vascular reactivity. In this model, elevations in extracellular glucose, through transport and metabolization (13), can activate a P2Y receptor coupled to $G_{s}$ signaling via extracellular nucleotide signaling (22) to specifically stimulate AC5 activity and localized production of CAMP. As AC5 is in close proximity to $\mathrm{Ca}_{\mathrm{v}} 1.2$, this CAMP microdomain may activate a pool of AKAP150-anchored PKA that is intimately associated with $\mathrm{Ca}_{v} 1.2$ to increase its phosphorylation at serine 1928 , leading to enhanced channel activity. This will result in an elevation in $\left[\mathrm{Ca}^{2+}\right]_{i}$ that modulates arterial myocyte contraction and myogenic tone. wide increase in cAMP production. In the context of arterial myocytes, in which it has been traditionally postulated that PKA is mainly involved in vasodilatory pathways (8), this glucose-elicited cAMP signaling is meaningful as it can induce activation of a pool of PKA targeted to a specific substrate (i.e., L-type $\mathrm{Ca}^{2+}$ channels) to influence a particular cellular response (i.e., contraction). Consistent with this view, application of forskolin in pressurized arteries resulted in vasodilation, even in the presence of elevated glucose (Supplemental Figure 3B and Supplemental Figure 5B). Thus, we submit that localized cAMP signaling provides a level of compartmentation that facilitates the specific stimulation of a pool of PKA that can potentiate L-type $\mathrm{Ca}^{2+}$ channel activity and vasoconstriction in response to elevated extracellular glucose, while likely averting activation of PKA-mediated vasodilatory pathways.

Multiple independent studies have found that arterial myocytes express several AC isoforms and that AC3, AC5, and AC6 are most abundantly expressed and may play significant functional roles in arterial myocytes (18-20). These studies reported a prevailing role for AC6, and to some extent $\mathrm{AC} 3$, in modulating vasodilatory signals through $\beta$-adrenergic stimulation and modulation of $\mathrm{K}^{+}$channel

\section{Discussion}

Myogenic autoregulation can be modulated by acute and chronic elevations in extracellular glucose (i.e., hyperglycemia). This may have profound implications as hyperglycemia is the major metabolic abnormality in diabetes and a key risk factor in the development and progression of vascular complications (1). Such elevations in glucose, either acutely or in animal models of diabetes, are often related to endothelium-dependent and -independent increase in vascular reactivity $(4,6-8,10,11,13,14,27$, $28,35,36,40,41)$. In this study, we made multiple fundamental discoveries regarding the mechanisms underlying alterations in vascular reactivity during hyperglycemia and diabetes (Figure 8). We found that acute elevations in extracellular glucose induced a subtle yet significant increase in cAMP synthesis that requires AC activity in arterial myocytes. Glucose-induced cAMP synthesis was mediated specifically by the AC5 isoform, which is in close proximity to the $\mathrm{Ca}_{\mathrm{v}} 1.2$ pore-forming subunit of the L-type $\mathrm{Ca}^{2+}$ channel. Glucose-induced AC5 activity mediated the activation of an anchored PKA pool, which, by phosphorylating $\mathrm{Ca}_{\mathrm{v}} 1.2$ at a single amino acid (serine 1928), causes potentiation of L-type $\mathrm{Ca}^{2+}$ channel activity, increased $\left[\mathrm{Ca}^{2+}\right]_{\mathrm{i}}$, and vasoconstriction. This chain of events underlies the potentiation of L-type $\mathrm{Ca}^{2+}$ channel activity and myogenic tone in 2 animal models of diabetes. These results suggest that AC5-driven L-type $\mathrm{Ca}^{2+}$ channel hyperactivity in arterial myocytes may be a general mechanism for increased myogenic tone during diabetic hyperglycemia.

Our first central observation was that elevating extracellular glucose led to a small yet significant increase in cAMP synthesis in arterial myocytes (Figure 1) that is reminiscent of localized cAMP production. Indeed, application of the broad AC activator forskolin induced an approximately 6-fold increase in cAMP in arterial myocytes compared with the glucose response, indicating a cellactivity (18-20). However, no involvement of AC5 in vasodilation could be defined (18), suggesting that this AC isoform could modulate other cellular responses. Consistent with this, we uncovered a critical functional role for AC5 in glucose-mediated cAMP synthesis and PKA-dependent L-type $\mathrm{Ca}^{2+}$ channel potentiation, as well as in the ex vivo and in vivo induction of vasoconstriction in response to increased extracellular glucose. This assertion is supported by data using pharmacological inhibition of AC with 2,5-DDA, which has nanomolar selectivity for AC5 $(31,32)$, as well as arterial myocytes from $\mathrm{AC5}^{-/-}$mice. Moreover, in a subset of experiments using arteries from $\mathrm{AC6}^{-/-}$mice, increased glucose was still able to induce vasoconstriction to the same extent as in WT arteries. These observations indicate divergent functional roles for AC5 and AC6 in arterial myocytes. Thus, our data indicate that selective activation of AC5 modulates local cAMP synthesis, L-type $\mathrm{Ca}^{2+}$ channel activity, and vascular reactivity in diabetic hyperglycemia. Furthermore, together with previous studies (18-20), our data highlight previously unappreciated cellular responses in arterial myocytes mediated by distinct AC isoforms.

Changes in AC activity have been linked to vascular dysfunction in rodent models of diabetes (52). A reduction in AC activity was suggested to underlie the impaired vasorelaxation of mesenteric arterial myocytes from STZ-induced diabetic rats, but the specific AC isoform underlying the changes was not identified (52). A recent comprehensive study in rat mesenteric arterial myocytes found that AC6 plays a major role in vasodilation through modulation of $\mathrm{K}^{+}$channels (18). Considering that $\mathrm{K}^{+}$channel function is impaired in arterial myocytes in response to elevated glucose and diabetes $(9,21,24,28,35,36,53)$, a decrease in AC6 signaling may also contribute to impaired vasodilation in diabetes. Our experiments further implicate activation of AC5 signaling as an essential component in the regulation of arterial myocyte L-type $\mathrm{Ca}^{2+}$ chan- 
nel function and vascular reactivity during diabetes. Consistent with this, increased arterial myocyte L-type $\mathrm{Ca}^{2+}$ channel activity and myogenic tone in HFD and STZ mouse models of diabetes were averted in $\mathrm{AC5}^{-/-}$mice on HFD and STZ (Figures 6 and 7). These results suggest a detrimental effect of AC5 signaling in arterial myocytes during diabetes. Moreover, results suggest that AC5 and AC6 may play unique yet critical roles in the vasculature. This is reminiscent of the distinctive roles for AC5 and AC6 in the heart, in which AC5 activity seems to contribute to age-related cardiomyopathy whereas AC6 signaling may be protective against cardiac hypertrophy $(54,55)$. Thus, divergent AC5 and AC6 signaling may have profound implications in multiple tissues and different physiological and pathological conditions, which could point toward these AC isoforms as potential therapeutic targets.

Our super-resolution nanoscopy and PLA analysis revealed broad distribution of $\mathrm{Ca}_{\mathrm{v}} 1.2$ and AC5 with subpopulations of both of these proteins closely associating with each other in arterial myocytes (Figure 5). The average distance between AC5 and $\mathrm{Ca}_{\mathrm{v}} 1.2$ pools in these cells was $53 \mathrm{~nm}$, with a subpopulation of AC5 centroids in closer proximity to $\mathrm{Ca}_{\mathrm{v}} 1.2$. This intimate spatial organization, which is less so between $\mathrm{Ca}_{\mathrm{v}} 1.2$ and AC6, may be necessary for local PKA-dependent regulation of L-type $\mathrm{Ca}^{2+}$ channels in arterial myocytes. In line with this, we recently showed a similar arrangement between $\mathrm{Ca}_{\mathrm{v}} 1.2$ and PKA in which subpopulations of these proteins are closely associated with each other $(\leq 40-90$ $\mathrm{nm}$ ) (13). The implication of these data is that pools of AC5 and PKA may be part of the same signaling complex and, if within an optimal distance to a subpopulation of $\mathrm{Ca}_{\mathrm{v}} 1.2$, can facilitate potentiation of L-type $\mathrm{Ca}^{2+}$ channels under conditions such hyperglycemia and/or diabetes. This possibility is supported by data indicating that close $\mathrm{Ca}_{\mathrm{v}} 1.2-\mathrm{PKA}$ association is required forglucosemediated potentiation of L-type $\mathrm{Ca}^{2+}$ channels (13), and findings in this study suggesting that increased $\mathrm{Ca}_{\mathrm{v}} 1.2$ and AC5 association may underlie potentiation of L-type $\mathrm{Ca}^{2+}$ channel activity and vasoconstriction in arterial myocytes from HFD and STZ mice (Figure 6, C and D). The results are evocative of a recent study by Tajada et al. suggesting that regulation of TRPV 4 channels by PKC during angiotensin II-mediated $\mathrm{G}_{\mathrm{q}}$ signaling in arterial myocytes is highly dependent on the distance between the ion channel and the kinase (56). Thus, our data provide additional support for an emerging model in which the boundaries for optimal, local, and graded modulation of an ion channel by signaling proteins, including $\mathrm{AC}$, are defined by distinctive distance constraints between members of the signaling complex.

The spatial relationship and PKA-dependent regulation of vascular $\mathrm{Ca}_{\mathrm{v}} 1.2$ channels by diabetic hyperglycemia are facilitated by the scaffolding protein A kinase anchoring protein 150 (AKAP150; murine ortholog of human AKAP79) (13). A wellrecognized mechanism by which the AC/cAMP signaling can be delimited to a particular substrate is through AKAPs, including AKAP79/150 (17). Data suggest that AKAP79/150 interacts with AC5 (57-59), and that this interaction, together with anchoring of PKA, is functionally relevant to compartmentalized $\beta$-adrenergic signaling in neurons (59). Thus, considering that AKAP150anchored PKA is essential for glucose-mediated potentiation of L-type $\mathrm{Ca}^{2+}$ channel activity and vasoconstriction (13), it is tempting to speculate that AC5 is a pivotal part of this macromolecular complex in arterial myocytes (Figure 8). This arrangement could facilitate optimal signaling among AC5, PKA, and $\mathrm{Ca}_{\mathrm{v}} 1.2$ to trigger contraction during hyperglycemia and diabetes. This possibility should be investigated in future experiments as it may add further insight into mechanisms by which glucose-mediated activation of PKA can lead to vasoconstriction.

A key remaining question is how AC5 is activated by diabetic hyperglycemia. $G \alpha_{s}$ protein-coupled receptors ( $G \alpha_{s}$ PCRs) are well-recognized activators of AC signaling. Thus, elevations in glucose could induce activation of a $\mathrm{G} \alpha_{\mathrm{s}} \mathrm{PCR}$ to stimulate AC5 activity. This will promote cAMP synthesis and PKA-mediated potentiation of L-type $\mathrm{Ca}^{2+}$ channel activity and vasoconstriction (Figure 8). Consistent with this possibility, we recently identified a $\mathrm{G}_{\mathrm{s}}$-coupled P2Y receptor that is activated by increases in extracellular nucleotides in response to elevated glucose to regulate cAMP synthesis, $\mathrm{Ca}_{\mathrm{v}} 1.2$ phosphorylation at serine 1928, L-type $\mathrm{Ca}^{2+}$ channel activity, and vascular reactivity (22). This $\mathrm{G}_{\mathrm{s}}$-coupled P2Y receptor could spatially organize within a specific pool of AC5, perhaps through AKAP79/150 scaffolding, to mediate optimal activation of this AC isoform in arterial myocytes in response to hyperglycemia. Future studies should comprehensively examine this model and its implications in diabetes.

In summary, our data indicate a central role for AC5 signaling in regulation of $\mathrm{L}$-type $\mathrm{Ca}^{2+}$ channel activity and vascular reactivity in response to elevations in extracellular glucose and diabetes. Results also highlight the significance of selective activation of AC isoforms in mediating distinctive cAMP signaling. This may have profound implications for the regulation of divergent processes such as vasodilation and vasoconstriction.

\section{Methods}

Detailed information on materials and experimental procedures is provided in Supplemental Methods.

Animals. Age-matched (5-8 weeks) male C57BL/6J WT, AC5 ${ }^{-/}$, $\mathrm{AC5}^{-/+}$, and $\mathrm{AC6}^{-/-}$mice were used. A subgroup of mice was put on either a low-fat diet (LFD; 10\% kcal) or a high-fat diet (HFD; 60\% kcal) (Research Diets) starting at 5 weeks of age. For other experiments, age-matched (8-12 weeks) WT and $\mathrm{AC5}^{-/-}$mice were injected with low doses of STZ to destroy pancreatic $\beta$ cells and induce hyperglycemia as previously described (48). All mice were euthanized by i.p. injection of pentobarbital $(250 \mathrm{mg} / \mathrm{kg})$. For metabolic characterization, blood samples from LFD, HFD, sham, and STZ mice were analyzed at the University of California, Davis, Mouse Biology Program facility.

Arterial myocyte isolation. Isolated mouse cerebral arterial myocytes were obtained from arteries digested in dissection buffer containing papain $(1 \mathrm{mg} / \mathrm{mL})$ and DTT $(1 \mathrm{mg} / \mathrm{mL})$, followed by incubation in dissection buffer containing collagenase type $\mathrm{F}(0.7 \mathrm{mg} / \mathrm{mL})$ and collagenase type $\mathrm{H}(0.3 \mathrm{mg} / \mathrm{mL})$. Cells were kept in ice-cold dissection buffer and used the same day. For unpassaged, cultured mouse arterial myocytes, mouse aortae were dissected out and incubated in a DMEM solution containing $2.2 \mathrm{mg} / \mathrm{mL}$ of collagenase Type II (Worthington) to remove the adventitia. Subsequently, arterial segments were incubated with $2.2 \mathrm{mg} / \mathrm{mL}$ of collagenase Type II (Worthington) with constant shaking to obtain isolated cells. Isolated arterial myocytes were seeded on glass coverslips coated with laminin.

Flow cytometry. Single cells were processed using a standard FACScan cytometer (BD Biosciences) upgraded to a dual laser system 
with the addition of a blue laser $(15 \mathrm{~mW}$ at $488 \mathrm{~nm})$ and a red laser (25 mW at $637 \mathrm{~nm}$; Cytek Development Inc.). Data were acquired and analyzed using CellQuest (BD Biosciences) and FlowJo software (version 9.7, Tree Star Inc.), respectively.

Adenovirus infection of arterial myocytes and FRET. Mouse aortic cells plated on laminin-coated coverslips were infected with virus coding for the membrane-targeted Epac1-camps-based FRET sensor (ICUE3-PM; refs. 29, 30). Viruses were produced using the AdEasy system (Qbiogene; ref. 60). A Zeiss AXIO Observer A1 inverted fluorescence microscope equipped with a Hamamatsu Orca-Flash 4.0 digital camera and controlled by Metaflor software (Molecular Devices) was used to acquire phase contrast, CFP480, and FRET images.

Transfection of arterial myocytes and confocal imaging. Unpassaged, primary cultured arterial myocytes seeded on Cell-Tak-coated coverslips (Thermo Fisher Scientific) were transfected with DNA constructs (1 $\mu \mathrm{g}$ DNA) for either the general endoplasmic reticulum marker Sec61ß-GFP (GenBank NM_006808; gift from Eammon J. Dickson, Department of Physiology and Membrane Biology, University of California, Davis) or ICUE3-PM or ICUE3-NLS (29, 30) using TransfeX transfection reagents following the manufacturer's instructions (ATCC). An Olympus FV1000 confocal microscope paired with an Olympus $\times 60$ oil immersion lens $(\mathrm{NA}=1.4)$ was used to collect images at different optical planes $(z$ axis, $0.5 \mu \mathrm{m})$. Images were processed offline using NIH ImageJ open software $(9,13)$.

Arterial diameter measurements. Freshly isolated cerebral artery segments were mounted in a 5-mL myograph chamber as described previously $(13,21,28)$ to determine arterial diameter changes in response to changes in extracellular glucose concentration and intraluminal pressure.

Electrophysiology. All experiments were performed at room temperature $\left(22^{\circ} \mathrm{C}-25^{\circ} \mathrm{C}\right)$ using the whole-cell patch-clamp technique with an Axopatch 200B amplifier and a Digidata 1440 digitizer (Molecular Devices). Analysis was performed using pClamp 10 (Molecular Devices).

Proximity ligation assay. A Duolink In Situ proximity ligation assay (PLA) kit (Sigma-Aldrich; ref. 39) was used to detect complexes containing AC5 and $\mathrm{Ca}_{\mathrm{v}} 1.2$ protein in freshly isolated cerebral arterial myocytes as previously described $(9,13)$. Imaging and analysis were performed as previously described using NIH Image J open software $(9,13,22)$.

In silico modeling. Simulations were performed using the Kapela et al. mathematical model of electrophysiology and $\mathrm{Ca}^{2+}$ dynamics in arterial myocytes (34) as recently adapted by our group (15).

Immunolabeling and GSD microscopy. Freshly dissociated arterial myocytes were fixed, labeled, and imaged as previously described (13, 22), using goat anti-AC5 (1:1000; sc74301, Santa Cruz Biotechnology) and custom rabbit anti-FP1 $(10 \mu \mathrm{g} / \mathrm{mL}$; ref. 61$)$ antibodies. Specificity of secondary antibodies was tested in control experiments in which primary antibodies were omitted from the preparation (no primary antibody control) or nonimmune isotype-specific immunoglobulins (i.e., rabbit IgG or goat $\operatorname{IgG}$ ) were used. Coverslips containing fixed and stained cells were mounted on a round-cavity microscope slide containing MEA-GLOX imaging buffer (NeoLab Migge LaborbedarfVertriebs $\mathrm{GmbH}$ ) and sealed with Twinsil (Picodent). Imaging was performed using a super-resolution ground state depletion (SR-GSD) system (Leica) dependent on stochastic single-molecule localization and equipped with high-power lasers $\left(532 \mathrm{~nm}, 2.1 \mathrm{~kW} / \mathrm{cm}^{2} ; 642 \mathrm{~nm}\right.$, $2.1 \mathrm{~kW} / \mathrm{cm}^{2} ; 405 \mathrm{~nm}, 30 \mathrm{~mW}$ ), a 160× HCX Plan-Apochromat (NA 1.47) oil immersion lens, and an electron-multiplying charge-coupled device (EMCCD) camera (iXon3 897; Andor Technology). Images were reconstructed from 30,000 images using the coordinates of centroids obtained by fitting of single-molecule fluorescence signals with a 2D Gaussian function in LASAF software (Leica). All pixels with intensity above a user-defined threshold were binarized, segmented into individual objects, and included as clusters in our analysis. Cluster size and density were determined using the Analyze Particle option in the Image J software (NIH). The JACoP plug-in in Image J was used to automatically determine the shortest intermolecular distances for $\mathrm{Ca}_{\mathrm{v}} 1.2$ and AC5 following the protocol described in ref. 62 .

Immunoblotting. Freshly isolated whole mouse brains were homogenized in a RIPA lysis buffer solution and cleared by centrifugation, and the supernatant was used as the whole-brain lysate. Proteins were separated by SDS-PAGE and then transferred to a PVDF membrane, which was blocked in 5\% nonfat dried milk before being incubated in primary antibody. Classico (Millipore) and Femto (Thermo Fisher Scientific) chemiluminescence reagents and exposure to $\mathrm{x}$-ray film were used to identify the bands. Densitometry analysis for bands was performed with ImageJ software (NIH). $\beta$-Actin was used for normalization of AC5 loading input (density expressed as percentage of $\beta$-actin).

Immunofluorescence. Freshly dissociated arterial myocytes were fixed, labeled, and imaged as previously described $(9,22,63,64)$, using a goat anti-AC5 antibody (1:1000; sc74301, Santa Cruz Biotechnology).

In vivo intravital imaging using cranial window. Mice were anesthetized with isoflurane and implanted with a cranial window. In vivo images were acquired using a Unitron Z850 stereomicroscope and StCamSWare software (Sentech America Inc.) and analyzed using NIH ImageJ.

Chemicals. All chemical reagents were from Sigma-Aldrich unless otherwise stated. A list of key reagents and resources is included in Supplemental Table 15.

Statistics. Data were analyzed using GraphPad Prism software and expressed as mean \pm SEM. Data were assessed for potential outliers using the GraphPad Prism Outlier Test and for normality of distribution. Statistical significance was then determined using appropriate paired or unpaired 2-tailed Student's $t$ test, nonparametric tests, or 1-way ANOVA for multiple comparisons with appropriate post hoc test. $P$ less than 0.05 was considered statistically significant (denoted by an asterisk in the figures).

Study approval. All animal studies strictly adhered to the approved Institutional Animal Care and Use Committee protocols (protocols 20321 and 20234) at University of California, Davis.

\section{Author contributions}

Due to the implementation of multiscale approaches that require different expertise, sharing of first author position was agreed upon before the start of the study. AUS took a leading role in collecting and organizing the figures provided by all authors. AUS, GRR, and DG designed and executed experiments; validated protocols; collected, analyzed, and interpreted data; and revised the manuscript. MPP, MAN, SM, and PS executed experiments, collected and analyzed data, and revised the manuscript. EG, NC, JWH, LFS, and YKX provided reagents and access to equipment, interpreted data, and revised the manuscript. MNC conceived and designed experiments; collected, analyzed, and interpreted data; and revised the manuscript. 
MFN conceived and designed experiments, interpreted data, and wrote and revised the manuscript.

\section{Acknowledgments}

We thank members of the Navedo laboratory for technical support and Eamonn J. Dickson for sharing the Sec61ß-GFP construct. This work was supported by NIH grants R01HL098200 and R01HL121059 (to MFN), T32HL086350 (to AUS and MAN), T32GM099608 (to MPP), R01HL131517 (to EG), R01HL142710 (to MAN), K99HL138160 (to SM), R01NS078792 and R01AG055357 (to JWH), and R01HL127764 and R01HL112413 (to YKX); Amer- ican Heart Association grants 16SDG27260070 (to MAN) and 18POST34060234 (to DG); a University of California, Davis, School of Medicine Dean's Fellow Award (to EG); and a University of California, Davis, Academic Federation Innovative Development Award (to MNC).

Address correspondence to: Manuel F. Navedo or Madeline Nieves-Cintrón, University of California, Davis, One Shields Avenue, Davis, California 95616, USA. Phone: 530.752.6880; Email: mfnavedo@ucdavis.edu (MFN). Phone: 530.754.0921; Email: mcnieves@ucdavis.edu (MNC).
1. American Diabetes Association. Standards of medical care in diabetes, 2017. Diabetes Care 2017;40:S1-S135.

2. Brown A, Reynolds LR, Bruemmer D. Intensive glycemic control and cardiovascular disease: an update. Nat Rev Cardiol. 2010;7(7):369-375.

3. Tousoulis D, et al. Diabetes mellitus-associated vascular impairment: novel circulating biomarkers and therapeutic approaches. J Am Coll Cardiol. 2013;62(8):667-676.

4. Cooper ME, Bonnet F, Oldfield M, Jandeleit-Dahm K. Mechanisms of diabetic vasculopathy: an overview. Am J Hypertens. 2001;14(5 pt 1):475-486.

5. Konzem SL, Devore VS, Bauer DW. Controlling hypertension in patients with diabetes. Am Fam Physician. 2002;66(7):1209-1214.

6. Montero D, Walther G, Pérez-Martin A, VicenteSalar N, Roche E, Vinet A. Vascular smooth muscle function in type 2 diabetes mellitus: a systematic review and meta-analysis. Diabetologia. 2013;56(10):2122-2133.

7. Sena CM, Pereira AM, Seiça R. Endothelial dysfunction - a major mediator of diabetic vascular disease. Biochim Biophys Acta. 2013;1832(12):2216-2231.

8. Tykocki NR, Boerman EM, Jackson WF. Smooth muscle ion channels and regulation of vascular tone in resistance arteries and arterioles. Compr Physiol. 2017;7(2):485-581.

9. Nieves-Cintrón $\mathrm{M}$, et al. Impaired $\mathrm{BK}_{\mathrm{C}}$ channel function in native vascular smooth muscle from humans with type 2 diabetes. Sci Rep. 2017;7(1):14058.

10. Aronson D. Hyperglycemia and the pathobiology of diabetic complications. Adv Cardiol 2008;45:1-16.

11. Nieves-Cintrón M, Syed AU, Nystoriak MA, Navedo MF. Regulation of voltage-gated potassium channels in vascular smooth muscle during hypertension and metabolic disorders. Microcirculation. 2018;25(1):e12423.

12. Navedo MF, Amberg GC. Local regulation of L-type $\mathrm{Ca}^{2+}$ channel sparklets in arterial smooth muscle. Microcirculation. 2013;20(4):290-298.

13. Nystoriak MA, et al. Ser1928 phosphorylation by PKA stimulates the L-type $\mathrm{Ca}^{2+}$ channel $\mathrm{Ca}_{\mathrm{v}} 1.2$ and vasoconstriction during acute hyperglycemia and diabetes. Sci Signal. 2017;10(463):eaaf9647.

14. Navedo MF, Takeda Y, Nieves-Cintrón M, Molkentin JD, Santana LF. Elevated $\mathrm{Ca}^{2+}$ sparklet activity during acute hyperglycemia and diabetes in cerebral arterial smooth muscle cells. Am J Physiol Cell Physiol. 2010;298(2):C211-C220.
15. Morotti S, Nieves-Cintrón M, Nystoriak MA, Navedo MF, Grandi E. Predominant contribution of L-type $\mathrm{Ca}_{\mathrm{v}} 1.2$ channel stimulation to impaired intracellular calcium and cerebral artery vasoconstriction in diabetic hyperglycemia. Channels (Austin). 2017;11(4):340-346.

16. Lemaire K, Van de Velde S, Van Dijck P, Thevelein JM. Glucose and sucrose act as agonist and mannose as antagonist ligands of the $G$ protein-coupled receptor Gpr1 in the yeast Saccharomyces cerevisiae. Mol Cell. 2004;16(2):293-299.

17. Dessauer CW, Watts VJ, Ostrom RS, Conti M, Dove S, Seifert R. International Union of Basic and Clinical Pharmacology. CI. Structures and small molecule modulators of mammalian adenylyl cyclases. Pharmacol Rev. 2017;69(2):93-139.

18. Nelson CP, et al. Principal role of adenylyl cyclase 6 in $\mathrm{K}^{+}$channel regulation and vasodilator signalling in vascular smooth muscle cells. Cardiovasc Res. 2011;91(4):694-702.

19. Ostrom RS, Liu X, Head BP, Gregorian C, Seasholtz TM, Insel PA. Localization of adenylyl cyclase isoforms and $G$ protein-coupled receptors in vascular smooth muscle cells: expression in caveolin-rich and noncaveolin domains. $\mathrm{Mol}$ Pharmacol. 2002;62(5):983-992.

20. Webb JG, Yates PW, Yang Q, Mukhin YV, Lanier $\mathrm{SM}$. Adenylyl cyclase isoforms and signal integration in models of vascular smooth muscle cells. Am J Physiol Heart Circ Physiol. 2001;281(4):H1545-H1552.

21. Nystoriak MA, et al. AKAP150 contributes to enhanced vascular tone by facilitating largeconductance $\mathrm{Ca}^{2+}$-activated $\mathrm{K}^{+}$channel remodeling in hyperglycemia and diabetes mellitus. Circ Res. 2014;114(4):607-615.

22. Prada MP, et al. A G -coupled purinergic receptor boosts $\mathrm{Ca}^{2+}$ influx and vascular contractility during diabetic hyperglycemia. Elife. 2019;8:e42214.

23. Barbagallo M, Shan J, Pang PK, Resnick LM. Glucose-induced alterations of cytosolic free calcium in cultured rat tail artery vascular smooth muscle cells. JClin Invest. 1995;95(2):763-767.

24. Rainbow RD, Hardy ME, Standen NB, Davies NW. Glucose reduces endothelin inhibition of voltage-gated potassium channels in rat arterial smooth muscle cells. JPhysiol (Lond). 2006;575(pt 3):833-844.

25. McGahon MK, et al. Diabetes downregulates large-conductance $\mathrm{Ca}^{2+}$-activated potassium $\beta 1$ channel subunit in retinal arteriolar smooth muscle. Circ Res. 2007;100(5):703-711.
26. Nilsson J, Nilsson LM, Chen YW, Molkentin JD, Erlinge D, Gomez MF. High glucose activates nuclear factor of activated T cells in native vascular smooth muscle. Arterioscler Thromb Vasc Biol. 2006;26(4):794-800.

27. Jarajapu YP, Guberski DL, Grant MB, Knot HJ. Myogenic tone and reactivity of cerebral arteries in type II diabetic BBZDR/Wor rat. Eur J Pharmacol. 2008;579(1-3):298-307.

28. Nieves-Cintrón M, et al. Selective downregulation of KV2.1 function contributes to enhanced arterial tone during diabetes. J Biol Chem. 2015;290(12):7918-7929.

29. Allen MD, et al. Reading dynamic kinase activity in living cells for high-throughput screening. ACS Chem Biol. 2006;1(6):371-376.

30. Liu S, Zhang J, Xiang YK. FRET-based direct detection of dynamic protein kinase A activity on the sarcoplasmic reticulum in cardiomyocytes. Biochem Biophys Res Commun. 2011;404(2):581-586.

31. Johnson RA, et al. Isozyme-dependent sensitivity of adenylyl cyclases to P-site-mediated inhibition by adenine nucleosides and nucleoside 3'-polyphosphates. JBiol Chem. 1997;272(14):8962-8966

32. Seifert R, Lushington GH, Mou TC, Gille A, Sprang SR. Inhibitors of membranous adenylyl cyclases. Trends Pharmacol Sci. 2012;33(2):64-78.

33. Timofeyev V, et al. Adenylyl cyclase subtypespecific compartmentalization: differential regulation of L-type $\mathrm{Ca}^{2+}$ current in ventricular myocytes. Circ Res. 2013;112(12):1567-1576.

34. Kapela A, Bezerianos A, Tsoukias NM. A mathematical model of $\mathrm{Ca}^{2+}$ dynamics in rat mesenteric smooth muscle cell: agonist and NO stimulation. J Theor Biol. 2008;253(2):238-260.

35. Jackson R, et al. Distinct and complementary roles for $\alpha$ and $\beta$ isoenzymes of PKC in mediating vasoconstrictor responses to acutely elevated glucose. Br J Pharmacol. 2016;173(5):870-887.

36. Straub SV, Girouard H, Doetsch PE, Hannah RM Wilkerson MK, Nelson MT. Regulation of intracerebral arteriolar tone by $\mathrm{K}(\mathrm{v})$ channels: effects of glucose and PKC. Am J Physiol Cell Physiol. 2009;297(3):C788-C796.

37. Buonarati OR, Henderson PB, Murphy GG, Horne MC, Hell JW. Proteolytic processing of the L-type Ca. F100ORes. 2017;6:1166.

38. Di Biase V, Tuluc P, Campiglio M, Obermair GJ, Heine M, Flucher BE. Surface traffic of dendritic CaV1.2 calcium channels in hippocampal neurons. J Neurosci. 2011;31(38):13682-13694.

39. Fredriksson S, et al. Protein detection using proximity-dependent DNA ligation assays. 
Nat Biotechnol. 2002;20(5):473-477.

40. Pannirselvam M, Wiehler WB, Anderson T, Triggle CR. Enhanced vascular reactivity of small mesenteric arteries from diabetic mice is associated with enhanced oxidative stress and cyclooxygenase products. Br J Pharmacol. 2005;144(7):953-960.

41. Creager MA, Lüscher TF, Cosentino F, Beckman JA. Diabetes and vascular disease: pathophysiology, clinical consequences, and medical therapy: part I. Circulation. 2003;108(12):1527-1532.

42. Winzell MS, Ahrén B. The high-fat diet-fed mouse: a model for studying mechanisms and treatment of impaired glucose tolerance and type 2 diabetes. Diabetes. 2004;53(suppl 3):S215-S219.

43. Kim F, et al. Vascular inflammation, insulin resistance, and reduced nitric oxide production precede the onset of peripheral insulin resistance. Arterioscler Thromb Vasc Biol. 2008;28(11):1982-1988.

44. Surwit RS, Kuhn CM, Cochrane C, McCubbin JA, Feinglos MN. Diet-induced type II diabetes in C57BL/6J mice. Diabetes. 1988;37(9):1163-1167.

45. Calligaris SD, et al. Mice long-term high-fat diet feeding recapitulates human cardiovascular alterations: an animal model to study the early phases of diabetic cardiomyopathy. PLoS One. 2013;8(4):e60931.

46. Islam MS, Loots du T. Experimental rodent models of type 2 diabetes: a review. Methods Find Exp Clin Pharmacol. 2009;31(4):249-261.

47. Heydemann A. An overview of murine high fat diet as a model for type 2 diabetes mellitus.
J Diabetes Res. 2016;2016:2902351.

48. Wu KK, Huan Y. Streptozotocin-induced diabetic models in mice and rats. Curr Protoc Pharmacol. 2008; Chapter 5:Unit 5.47.

49. Berglund ED, et al. Glucose metabolism in vivo in four commonly used inbred mouse strains. Diabetes. 2008;57(7):1790-1799.

50. Warden CH, Fisler JS. Comparisons of diets used in animal models of high-fat feeding. Cell Metab. 2008;7(4):277.

51 . Ho D, et al. Adenylyl cyclase type 5 deficiency protects against diet-induced obesity and insulin resistance. Diabetes. 2015;64(7):2636-2645.

52. Matsumoto T, Wakabayashi K, Kobayashi T, Kamata K. Functional changes in adenylyl cyclases and associated decreases in relaxation responses in mesenteric arteries from diabetic rats. Am J Physiol Heart Circ Physiol. 2005;289(5):H2234-H2243.

53. Liu Y, Terata K, Rusch NJ, Gutterman DD. High glucose impairs voltage-gated $\mathrm{K}(+)$ channel current in rat small coronary arteries. Circ Res. 2001;89(2):146-152.

54. Tang T, et al. Adenylyl cyclase type 6 deletion decreases left ventricular function via impaired calcium handling. Circulation. 2008;117(1):61-69.

55 . Yan L, et al. Type 5 adenylyl cyclase disruption increases longevity and protects against stress. Cell. 2007;130(2):247-258.

56. Tajada S, et al. Distance constraints on activation of TRPV4 channels by AKAP150-bound PKC $\alpha$ in arterial myocytes. JGen Physiol. 2017;149(6):639-659.
57. Efendiev R, et al. AKAP79 interacts with multiple adenylyl cyclase (AC) isoforms and scaffolds AC5 and - 6 to $\alpha$-amino-3-hydroxyl-5-methyl-4-isoxazole-propionate (AMPA) receptors. J Biol Chem 2010;285(19):14450-14458.

58. Bauman AL, et al. Dynamic regulation of cAMP synthesis through anchored PKA-adenylyl cyclase V/VI complexes. Mol Cell. 2006;23(6):925-931.

59. Zhang M, et al. Adenylyl cyclase anchoring by a kinase anchor protein AKAP5 (AKAP79/150) is important for postsynaptic $\beta$-adrenergic signaling. J Biol Chem. 2013;288(24):17918-17931.

60. Luo J, et al. A protocol for rapid generation of recombinant adenoviruses using the AdEasy system. Nat Protoc. 2007;2(5):1236-1247.

61. Davare MA, Horne MC, Hell JW. Protein phosphatase $2 \mathrm{~A}$ is associated with class $\mathrm{C}$ L-type calcium channels $\left(\mathrm{Ca}_{\mathrm{v}} 1.2\right)$ and antagonizes channel phosphorylation by cAMP-dependent protein kinase. J Biol Chem. 2000;275(50):39710-39717.

62. Bolte S, Cordelières FP. A guided tour into subcellular colocalization analysis in light microscopy. JMicrosc. 2006;224(pt 3):213-232.

63. Navedo MF, Amberg GC, Nieves M, Molkentin JD, Santana LF. Mechanisms underlying heterogeneous $\mathrm{Ca}^{2+}$ sparklet activity in arterial smooth muscle. J Gen Physiol. 2006;127(6):611-622.

64. Navedo MF, et al. AKAP150 is required for stuttering persistent $\mathrm{Ca}^{2+}$ sparklets and angiotensin II-induced hypertension. Circ Res. 2008;102(2):e1-e11. 